\title{
12. Stufenweise Deeskalation der Berlin-Krise
}

\author{
Bemühungen nach der Kuba-Krise
}

Unmittelbar nach der Kuba-Krise, am 30. Oktober 1962, appellierte Chruschtschow brieflich an Kennedy, der Übereinkunft in der Karibik eine ebensolche Übereinkunft folgen zu lassen, die der Lage in Deutschland Rechnung trage. Dort seien zwei oder vielmehr - bei Einrechnung West-Berlins - drei Staaten entstanden, zwischen denen sich spezifische Beziehungen gebildet hätten. Es sei nicht mehr angebracht, den Verkehr der Stadt mit der Außenwelt über das Territorium der DDR noch von „irgendwelchen Substituten von Verträgen“ zu regeln, auch wenn die formal noch gar nicht existierenden Verträge faktisch schon in Kraft getreten seien. Mithin, so folgerte er, sei man sich schon über alles außer über die Frage der Truppen in West-Berlin einig. Auch dabei sei nur noch zu klären, von welchen Staaten sie gestellt und unter welcher Flagge sie tätig werden sollten. Natürlich komme die Regelung nur während einer noch festzulegenden Zeitspanne in Betracht. Könne man sich denn darüber nicht verständigen? Ein Interesse daran, daß die Lage ungelöst bleibe, hätten weder die USA noch die UdSSR, sondern nur die „revanchistischen Kräfte“, nämlich Adenauer und andere, welche die als Folge der Niederlage im Zweiten Weltkrieg entstandene Lage nicht anerkennen wollten. ${ }^{1}$

Am 2. November begab sich Ulbricht nach Moskau. ${ }^{2}$ Die Reise war schon vor der Kuba-Krise geplant worden und sollte, nach der Zusammensetzung der Delegation zu urteilen, wesentlich der Erörterung wirtschaftlicher Themen dienen. ${ }^{3}$ Welche politischen Wünsche der SED-Chef hatte, war deutlich geworden in einer Unterredung mit Gromyko am 23. Oktober, unmittelbar nach Kennedys Erklärung zur Stationierung der sowjetischen Raketen in der Karibik. Ulbricht hatte den Vorwurf wiederholt, die USA suchten die West-Berlin-Regelung auf die lange Bank zu schieben, und sich darauf berufen, die UdSSR habe den baldigen Abschluß des Friedensvertrags zugesichert. Nach der Aufzeichnung, die er dem Außenminister übergeben hatte, sollte dem Westen ein „äußerster Kompromiß“ angeboten werden. ${ }^{4}$

1 N. S. Chruščëv an J. F. Kennedy, 30. 10. 1962, Foreign Relations of the United States (FRUS) 19611963, Bd. VI: Kennedy-Khrushchev Exchanges, Washington 1996, S. 190-198.

2 A. A. Fursenko, Kak byla postroena berlinskaja stena, in: Istoričeskie zapiski, 4 (122), S. 89.

3 Einladungsschreiben an die Mitglieder und Kandidaten des Politbüros der SED zur Sitzung am 23. 10. 1962, 20. 10. 1962, SAPMO-BArch, DY 30/J IV 2/2 A-930, Bl. 1; Protokoll Nr. 47/62 der Sitzung des Politbüros der SED, 24. 10. 1962, SAPMO-BArch, DY 30/J IV 2/2, Bl. 4-10.

4 Gespräch A. A. Gromyko - W. Ulbricht, 23. 10. 1962, AVPRF, 0742, 7, 51 4, B1. 54-62. 
In Abwandlung eines Vorschlags, den Dobrynin am 12. Juli in Washington unterbreitet hatte, ${ }^{5}$ regte Ulbricht im Kreml an, den drei Weststaaten in West-Berlin für eine bestimmte Frist eigene, nicht durch Kontingente anderer Länder erweiterte Polizeikräfte unter UNO-Flagge zuzugestehen, sofern unzweideutig klar sei, daß es keine originären Siegerrechte mehr gebe und die Vier-Mächte-Abkommen ihre Gültigkeit verloren hätten. Unabdingbar seien nur „die Beseitigung des Besatzungsregimes und die Ausschaltung jeglichen Einflusses der NATO auf Westberlin“. Die drei westlichen Staaten durften demnach weder staatliche Gewalt ausüben noch Anspruch auf Zugang erheben. Der UNO seien ebenfalls keine Vollmachten einzuräumen; die ihr unterstellten Kräfte hätten nur die Einhaltung des Freistadt-Statuts zu gewährleisten und „Einmischungsversuche“ Bonns abzuwehren. ${ }^{6}$ Was Ulbricht zu der Anregung bewog, ist unklar. Er glaubte wohl kaum, daß die USA zu einer Einigung auf dieser Basis bereit sein würden. Vielleicht hoffte er, Chruschtschow werde sich nach einem amerikanischen Nein zu einem solchen letzten Angebot der Einsicht nicht mehr verschließen können, daß nur noch der Abschluß des Separatfriedensvertrages in Betracht komme.

Die Kennedy-Administration ging nach der Kuba-Krise mit gestärktem Selbstvertrauen in die Gespräche über Berlin und Deutschland und widersprach der sowjetischen These, bezüglich des Friedensvertrags seien schon so gut wie alle Probleme gelöst, so daß eine Übereinkunft rasch erzielt werden könne. In der Streitfrage, ob die Westmächte mit vollen Rechten in West-Berlin bleiben sollten, sah man in Washington keine Bagatelle, sondern den Kern eines unverminderten Gegensatzes zwischen unvereinbaren Positionen. Mit der auf Besatzungsrecht - nicht vertraglicher Erlaubnis - beruhenden Anwesenheit in der Stadt stand und fiel nach amerikanischer Auffasung das Engagement für die Sicherheit der europäischen Verbündeten. Wie das State Department am 13. November einem sowjetischen Diplomaten zu verstehen gab, bestand das Einvernehmen noch nicht, das seine Regierung als unerläßliche Voraussetzung für Vier-Mächte-Verhandlungen betrachtete. ${ }^{7}$ In folgenden Besprechungen zwischen Präsident Kennedy und Bundeskanzler Adenauer wurde zudem klar, daß sich der Bonner Widerstand gegen jede Aufweichung der westlichen Position in Berlin versteift hatte. ${ }^{8}$

Am 28. November formulierte Außenminister Rusk Instruktionen für die Fortsetzung des Gesprächs mit der sowjetischen Seite. Als „Ziel mit hoher Priorität“ faßte er ins Auge eine „solide Regelung in Berlin zu Bedingungen, welche die Stadt frei und funktionsfähig erhält". Jede Gelegenheit zu einem solchen Einvernehmen sollte genutzt werden. In der augenscheinlichen Absicht, den USA neue Konzessionsangebote zu ersparen, wollte er der sowjetischen Seite die Initiative $\mathrm{zu}$ neuen Vorschlägen überlassen. Abmachungen allein auf westliche Kosten schloß er ausdrücklich aus. Zugleich zeigte er deutliches Interesse an der von Chruschtschow geäußerten Idee, daß die Westmächte vielleicht unter UNO-

\footnotetext{
5 Memorandum of Conversation (Rusk - Dobrynin), 12. 7. 1962, FRUS 1961-1963, XV, S. 215.

6 Westberlin betreffende Fragen, 22. 10. 1962, PA-MfAA, G-A 491, Bl. 1-14.

Memorandum of Conversation [Hillenbrand - Kornienko], 13.11. 1962, in: FRUS 1961-1963, XVI, S. $425 \mathrm{f}$.

8 Memorandum of Conversation, 14.11. 1962, ebd., S. 427-433; Memorandum of Conversation, 14. 11. 1962, ebd., S. 433-443.
} 
Flagge weiter in Berlin bleiben könnten. ${ }^{9}$ In Washington war aber nicht bekannt, welche näheren Vorstellungen dem Gedanken zugrunde lagen und daß die Anregung diesmal von Ulbricht ausgegangen war. ${ }^{10}$

\section{Anzeichen für einen Kurswechsel des Kreml?}

Nach Beilegung der Kuba-Krise wandte sich die östliche Seite mehrfach an die Öffentlichkeit mit Aussagen, die ein Abrücken von den alten Forderungen anzuzeigen schienen. Am 7. November versicherte Chruschtschow ausländischen Journalisten in Moskau, der UdSSR gehe es nicht darum, sich West-Berlins durch den geforderten Friedensvertrag zu bemächtigen. Vielmehr wolle sie den Frieden gewährleisten, der durch die Stadt bedroht werde. In Washington wurde positiv vermerkt, daß der Kremlchef nicht auf einem Termin für den Vertragsabschluß bestand, sondern erklärte, daß die Zeit dafür heranreife. Anders als bei früheren Gelegenheiten legte er zudem den Akzent nicht nur auf die Berlin-Frage, sondern betonte nachdrücklich sein Interesse an Schritten zur Beendigung der Kernwaffentests und zur Beschränkung der Rüstungen. ${ }^{11}$ Etwa zur gleichen Zeit gab er die Absicht zu erkennen, den Westmächten die Fortdauer ihrer ausschließlichen Präsenz in West-Berlin zeitweilig zuzugestehen, wenn sie dafür den siegerrechtlichen Rechtsanspruch fallenließen. ${ }^{12}$ Als aber die kanadische Seite Genaueres wissen wollte, verweigerte er jede Erläuterung mit dem Bemerken, die Offerte sei „hinreichend klar“. Daraus zog man im Westen der Schluß, vorerst sei keine sowjetische Initiative zu erwarten. Chruschtschow wolle nur eine Verschärfung des Berlin-Konflikts vermeiden, ohne den Eindruck zu erwecken, daß dessen Regelung auf die lange Bank geschoben werden könne. ${ }^{13}$ In diesem Sinne wurde auch die nicht weiter erläuterte briefliche Mitteilung an Macmillan verstanden, Friedensvertrag und Normalisierung in West-Berlin seien vordringlich. ${ }^{14}$

Der sowjetische Botschafter in London legte freilich Außenminister DouglasHome Ideen zu einem „Kompromiß“ dar. Nachdem die UdSSR bereits früher Zugeständnisse gemacht habe, sei sie nun bereit, die Frage der westlichen Streitkräfte in West-Berlin zu regeln. Wenn die Besatzungsflagge, die in Wirklichkeit

9 Telegram From the Department of State to the Embassy in the Soviet Union, 28.11. 1962, ebd., S. 446-449.

10 Vgl. Roger Hilsman, Soviet Intentions Toward Berlin Negotiations, 7. 12. 1962, National Security Archive, The Berlin Crisis, 1958-1962, published by Chadwick-Healey, Alexandria, VA, microfiche 02894, Bl. 1-8.

11 N. S. Chruschtschow auf Empfang im Moskauer Kreml: Wir waren Kernwaffenkrieg sehr nahe, aber die Vernunft hat gesiegt! in: Neues Deutschland, 8. 11. 1962.

12 Hinweise auf die bei der Verabschiedung des britischen Botschafters gemachte Aussage (am 13.11. 1962 oder möglicherweise etwas früher) in: FRUS 1961-1963, XV, S. 438 (Fußnote 3); Fernschreiben von Botschafter Gröpper aus Moskau (über Unterrichtung durch den britischen Botschafter über sein Gespräch mit Chruščëv), 14. 11. 1962, PA, B 130, 3928 (als Einzeldokument freigegeben unter 117-251.07/S. 1-8; Ref. 704, 704.8301/94.29/1995/62), Bl. 5 f.

13 Fernschreiben von Botschafter Gröpper aus Moskau (über Unterrichtung durch den kanadischen Botschafter über sein Gespräch mit Chruščèv), 13. 12. 1962 (als Einzeldokument freigegeben unter 117-251.07/S. 1-3; Ref. 704, 704.8301/94.29/1995/62), PA, B 130, 3928, Bl. 5 f.

14 N. S. Chruščèv an H. Macmillan (dte. Übers.), 27. 11. 1962 (als Einzeldokument freigegeben unter 117-251.07/ S. 1-7; Ref. 704, 704.8301/94.29/1995/62), PA, B 130, 3941a, Bl. $6 f$. 
ein „Deckmantel für die NATO“ sei, durch die Fahne der UNO ersetzt werde, könnten die Truppen der Westmächte für eine gewisse Zeit zusammen mit Kräften anderer Länder als Polizisten unter UNO-Kommando in der Stadt bleiben. In diesem Fall würden die Vereinten Nationen „selbst gewisse internationale Verpflichtungen gegenüber Westberlin“ übernehmen; ihr Sitz könnte dorthin verlegt werden. ${ }^{15}$ Mikojan meinte im Gespräch mit Rusk, nach Beseitigung der Kriegsgefahr in Kuba müsse man diese auch in Deutschland ausräumen. Die Sowjetunion könne nicht über Chruschtschows Vorschläge hinausgehen. Er fragte polemisch, ob denn die USA, die nichts Neues vorlegten und keine konstruktiven Anstrengungen machten, glaubten, ewig ihre Besatzungstruppen in der Stadt lassen zu können. Der amerikanische Außenminister entgegnete, auf dieser Grundlage werde es keine Vereinbarung geben. Es bedürfe eines Entgegenkommens auch der UdSSR. ${ }^{16}$ In Washington hatte man den Eindruck, Mikojan habe ohne neue Instruktionen nur den alten Standpunkt wiederholt. ${ }^{17}$

Eine Unterredung zwischen Botschafter Kohler und dem sowjetischen Spitzendiplomaten Semjonow in Moskau am 3. Dezember führte ebenfalls nicht weiter. Während der Amerikaner betonte, ein Rückzug der Westmächte aus Berlin komme nicht in Betracht, gab sein Gesprächspartner der Erwartung Ausdruck, man könne aufgrund der bestehenden Verhältnisse (die nach Moskauer Ansicht durch das Faktum dreier Staaten in Deutschland bestimmt wurden) zu einer Regelung gelangen. Beide Seiten könnten dazu einen nützlichen Beitrag leisten, wenn sie die vorgetragenen Positionen in Übereinstimmung miteinander bringen würden. Wieder gab es keinen Vorschlag, wie sich der Gegensatz in der Berlinund Deutschland-Frage überwinden lasse. ${ }^{18}$ Eine Stellungnahme Ulbrichts in Cottbus am 2. Dezember wurde aber im Westen als Indiz einer weniger harten östlichen Haltung gewertet. Danach galt es, „mit Hilfe der friedlichen Koexistenz Kriege zu verhindern.“ Das erfordere „die Bereitschaft, gefährliche Streitfragen auf dem Wege von Verhandlungen zu klären und bestimmte Vereinbarungen zu treffen“, und sei „mit Kompromissen beider Seiten“ verbunden. ${ }^{19}$ Diese Stellungnahme wurde zwar im Blick auf die Kuba-Krise abgegeben, konnte aber ebenso auf Berlin bezogen werden.

Am 11. Dezember wies Chruschtschow am Ende eines langen Schreibens an Kennedy ein weiteres Mal darauf hin, daß die Frage der Truppen in West-Berlin gelöst werden müsse, und gab Adenauer alle Schuld daran, daß es darüber noch zu keiner Einigung gekommen sei. Er stellte die rhetorische Frage, ob denn beide

15 Protokoll des Gesprächs Lord Home - Botschafter Soldatov (dte. Übers.), 28. 11. 1962 (als Einzeldokument freigegeben unter 117-251.07/ S. 1-4; Ref. 704, 704.8301/94.29/1995/62), PA, B 130, 3941a, Bl. 1-3.

16 Memorandum of Conversation, 30. 11. 1962, in: FRUS 1961-1963, XV, S. 449-452.

17 Department of State, Outgoing Telegram, 3. 12. 1962, National Security Archive, The Berlin Crisis, 1958-1962, published by Chadwick-Healey, Alexandria, VA, microfiche 02892, Bl. $1 \mathrm{f}$.

18 Telegram From the Embassy in the Soviet Union to the Department of State, 3.12. 1962, ebd., S. 453-457; Aufzeichnung von V. S. Semënov über Frühstück mit F. Kohler, 3. 12. 1962 (von Gromyko am 9. 12. 1962 den Mitgliedern und Kandidaten des ZK-Präsidiums übersandt), AVPRF, 0129, 46, 346, 12, Bl. 100-112.

19 Auszug aus der Rede Ulbrichts auf der Tagung der Bezirksdelegiertenkonferenz Cottbus der SED, 2. 12. 1962, in: Dokumente zur Deutschlandpolitik, hrsg. vom Bundesministerium für Innerdeutsche Beziehungen, IV. Reihe, Bd. 8/2, Frankfurt/Main 1977, S. 1453. 
Großmächte ihre Interessen weiterhin einem alten Mann unterordnen wollten, der moralisch wie physisch schon mit einem Bein im Grabe stehe. Solle man denn wirklich zu „Spielzeug“ in seinen Händen werden? Den „äußerst aggressiven militaristischen Kräften in Westdeutschland“ dürfe nicht länger gestattet werden, die gesamte Welt in Gefahr zu bringen. Mit dem Abschluß des Friedensvertrages, so erklärte der Kremlchef zum wiederholten Mal, verliere man nichts, gewinne aber die Möglichkeit, beiderseitig die freundlichen Beziehungen zu stärken und die gefährlichen Konflikte in Europa zu entwirren. ${ }^{20}$ Chruschtschow dürfte kaum geglaubt haben, mit dieser groben Polemik dem amerikanischen Präsidenten die Forderungen der UdSSR nahezubringen. Ging es ihm überhaupt noch um eine Berlin-Regelung?

Am 12. Dezember erklärte der Kremlchef vor dem Obersten Sowjet, die westlichen Staatslenker müßten berücksichtigen, daß die Katastrophe eines Nuklearkrieges drohe, wenn man Streitfragen „von der Politik der Stärke aus“ lösen wolle. Die chinesische Kritik am Nachgeben der UdSSR in Kuba wies er mit dem Argument zurück, ein „dogmatisches Herangehen ohne nüchterne Einschätzung der realen Umstände“ sei schädlich. Es gehe nicht an, Konflikte durch Krieg statt durch Verhandlungen zu lösen. Natürlich müsse man den „Imperialismus“ - wie man in Moskau den Westen und vor allem die USA nannte - „entlarven“, aber dieser werde durch bloßes Beschimpfen nicht geschwächt. Auch wenn er (wie man in Peking erklärte) nur ein „papierener“ Tiger wäre, so habe er doch nukleare Zähne. Daher müsse man im Verhältnis zu den imperialistischen Ländern einerseits Kompromisse schließen und andererseits alle Mittel haben, um die Aggressoren zu zerschlagen, wenn sie einen Krieg entfesselten. Chruschtschow nahm nur kurz auf den Friedensvertrag und die Normalisierung der Lage in West-Berlin Bezug. Nachdem der Konfliktherd in Kuba ausgeräumt sei, müsse auch dieser Streit ein Ende finden. Er wiederholte, es gehe im wesentlichen nur noch darum, „in welcher Eigenschaft, unter welcher Flagge“ die Truppen in der Stadt stünden und wie lange sie dort blieben. Sie sollten nicht „die Länder der NATO vertreten“, sondern ihre Fahne durch die der UNO ersetzen, die daraufhin „dort bestimmte internationale Verpflichtungen und Funktionen übernehmen“ würde. Wer im Westen darauf hoffe, daß es die UdSSR an Entschiedenheit fehlen lassen werde, täusche sich. ${ }^{21}$ Gromyko wiederholte am nächsten Tag, was der Parteichef als sowjetischen Standpunkt zur Sache formuliert hatte. ${ }^{22}$

Am 14. Dezember gab Ulbricht in Ausführungen über Wirtschaftsfragen die Parole aus, man müsse sich vom „Dogmatismus“ befreien. Jeder müsse „verstehen, daß in der Zeit, wo der Kampf zwischen der sozialistischen DDR und dem staatsmonopolistisch-kapitalistischen Westdeutschland bei offener Grenze geführt wurde, eben der politische Kampf im Vordergrund stand und stehen mußte." Anders als im Meinungsaustausch mit Chruschtschow vor der KubaKrise räumte er ein, daß sich die Lage seit „Sicherung der Staatsgrenze“ im August 1961 geändert habe. Bis dahin hätten eine „Reihe ökonomischer Gesetze des So-

20 N. S. Chruščëv an J. F. Kennedy, 11. 12. 1962, FRUS 1961-1963, VI, S. 229 f.

21 Rechenschaftsbericht Chruščëvs, 12. 12. 1962, in: Pravda, 13. 12. 1962.

22 Rede des Deputierten Gromyko, 13. 12. 1962, in: Pravda, 14. 12. 1962. 
zialismus nicht konsequent angewandt werden“ können und seien „sogar weitgehend verletzt" worden. Nachdem aber mit der Grenzschließung das zugrunde liegende politische Problem gelöst worden sei, hätten „jetzt die ökonomischen Aufgaben den Vorrang“. Die wirtschaftliche Stärkung der DDR und die Lösung der Aufgaben beim umfassenden Aufbau des Sozialismus seien nunmehr entscheidend, wenn die deutsche Frage in der angestrebten Weise gelöst werden solle. ${ }^{23}$ Das lief unausgesprochen auf die Schlußfolgerung hinaus, daß Friedensvertrag und Freistadtregelung im Grunde unwichtig seien.

Politikern im Westen fiel zunehmend auf, daß der Kreml, der bis zur KubaKrise stark auf eine Vereinbarung über West-Berlin und Deutschland gedrängt hatte, keine neue Initiative startete und sich anderen Problemen zuwandte. Die Frage, ob man das Interesse verloren habe, wurde jedoch von der sowjetischen Seite mit einem klaren Nein beantwortet. ${ }^{24}$ Auch gegenüber der DDR hieß es, die Haltung sei unverändert. Gromykos erwähnte Rede vor dem Obersten Sowjet beweise, daß die UdSSR es auf die Dauer nicht hinnehme, wenn die Westmächte nicht ernsthaft verhandelten. ${ }^{25}$ Der Kreml bekundete Zuversicht, daß die USA früher oder später bereit sein würden, eine Regelung zu akzeptieren. Intern war davon die Rede, der Westen werde unter zunehmenden internationalen Druck geraten, falls er den sowjetischen Vorstellungen nicht folge. Seit der Kuba-Konflikt beigelegt sei, forderten immer mehr neutrale Regierungen, nun müsse auch der Gefahrenherd West-Berlin durch Kompromisse entschärft werden. ${ }^{26}$

\section{Abrücken von der bisherigen Berlin-Politik}

Chruschtschow stellte zwar nach außen hin den Ausgang der Kuba-Krise als Triumph seiner Politik hin, die den Frieden gerettet und den Verzicht der USA auf die Aggression gegen die Karibikinsel erzwungen habe, war sich aber in Wirklichkeit seiner Niederlage bewußt und erkannte, daß der militärische Bluff, auf dessen Wirkung er sich seit 1958 verlassen hatte, keinen Erfolg versprach. ${ }^{27}$ Das erklärte er für vertretbar, denn die Lage in Berlin entwickele sich auch ohne Friedensvertrag positiv. Die Sperrung der Sektorengrenze habe „tiefgreifenden Einfluß auf das innere Leben West-Berlins ausgeübt“. Die westlichen Möglichkeiten, die Stadt als „Zentrum der subversiven Tätigkeit“ gegen die DDR zu nutzen, seien stark eingeschränkt worden; der Versuch, „die reale Lage [in Deutschland] zu revidieren“, sei gescheitert. Die Isolierung West-Berlins vom Umland, seine geographische Distanz zur Bundesrepublik, der fehlende Zustrom ostdeutscher Arbeitskräfte und die Ungewißheit über die Zukunftsperspektiven zögen in der Bevölkerung Niedergeschlagenheit und Konzessionsbereitschaft nach sich, was in Bonn

23 Antwort auf die Fragen der Delegierten. Aus der Diskussionsrede des Genossen Walter Ulbricht auf der Bezirksdelegiertenkonferenz in Leipzig, in: Neues Deutschland, 15. 12. 1962.

24 Vgl. z. B. Gespräch G. I. Slavin - E. Bahr, 22. 12. 1962, RGANI, 5, 49, 489 (rolik 9019), Bl. 1-3.

25 Aktenvermerk über Gespräch der Genossen der 1. Europ. Abteilung des MfAA auf Freundschaftsabend in sowjetischer Botschaft am 7. 12. 1962, 11. 12. 1962, PA-MfAA, A 546, Bl. 302-304.

26 Krolikowski: Information über Gespräch mit Botschaftsrat Žiljakov am 12.1. 1963, 12. 1. 1963, PA-MfAA, A 546, Bl. 298-300.

27 William Taubman, Khrushchev. The Man and his Era, New York-London 2003, S. 578-581. 
große Unruhe hervorrufe. Auch wenn die westdeutsche Seite enorme materielle Anstrengungen mache, lahme die West-Berliner Wirtschaft. Intelligenz, Unternehmer und Mittelschichten wanderten ab. Die Autorität von Bundesregierung und CDU sei stark unterminiert; die These, daß die Westmächte für die Stadt einträten, stoße weithin auf Mißmut und Skepsis.

Gleichzeitig wurde freilich auch ein deutliches Anwachsen feindseliger Stimmungen gegenüber der DDR und der SED festgestellt, die sich vor allem in der Jugend, auch bei jungen Arbeitern, in den Gewerkschaften und in den Massenorganisationen verbreiteten. Jedes Anzeichen eines verschärften Regimes an den Zugangswegen rufe Unruhe in der Stadt hervor und lasse Gerüchte über eine erneut drohende Blockade entstehen. Zugleich wiesen die sowjetischen Beobachter auf eine zunehmende Tendenz hin, eine Normalisierung der Lage und den Abschluß eines Interimsabkommens zu befürworten. ${ }^{28}$ Chruschtschow erklärte, die West-Berlin-Frage sei schon so gut wie gelöst und bedürfe keiner weiteren Regelung. ${ }^{29}$ Damit verband sich die von Ulbricht abgelehnte Absicht, die UdSSR solle sich in West-Berlin durch die Anbahnung intensiver wirtschaftlicher, kultureller, wissenschaftlicher und sonstiger Kontakte zu dortigen Institutionen und Organisationen immer mehr als faktische vierte Statusmacht etablieren. ${ }^{30}$

Die gleichzeitige Erwartung, die westliche Position werde sich fortlaufend verschlechtern, ließ den Verzicht auf weiteres Drängen vertretbar erscheinen. Das Neujahrsschreiben Chruschtschows an Ulbricht hob zwar die „Notwendigkeit und Unaufschiebbarkeit der herangereiften internationalen Fragen “ hervor, deren „ungeregelter Zustand eine ernste Gefahr für den Weltfrieden“ in sich berge, wiederholte aber im übrigen nur formelhaft das Verlangen nach „Beseitigung der Überreste des zweiten Weltkrieges“, nach „Abschluß des deutschen Friedensvertrages“ und nach „Normalisierung der Lage in Westberlin auf dessen Grundlage“.31 In einem Interview für die britische Zeitung „Daily Express“ zeichnete der Kremlchef das Bild einer friedensgefährdenden Situation in der Stadt, die durch Erfüllung der sowjetischen Forderungen entschärft werden müsse. Dazu bedürfe es noch „letzter Anstrengungen“. Die damit gestellte Aufgabe müsse „auf vernünftiger Basis“ gelöst werden. Als „Kompromiß“ schlug er nochmals vor, die westliche Garnison durch Truppen weiterer Länder zu ergänzen und die Flagge der NATO durch die der UNO zu ersetzen. ${ }^{32}$ Darauf lag freilich kein Nachdruck, wie daran abzulesen ist, daß das sowjetische Parteiorgan in den folgenden zwei Wochen nur noch einen Artikel brachte, in dem von Berlin die Rede war. ${ }^{33}$

28 G. Žiljakov/Ju. Kvicinskij, Ob ekkonomičeskom i vnutripolitičeskom položenii Zapadnogo Berlina v 1962 godu (Spravka), 20. 3. 1963, AVPRF, 0742, 8, 61, 22, B1. 52-90.

29 W. Taubman, a.a.O., S. 582 f. Der sowjetische ZK-Apparat hatte bereits im Februar 1962 die Einschätzung formuliert, der Westen sehe sich in der Inselstadt zunehmenden Schwierigkeiten gegenüber: I. Kabin an das ZK der KPdSU, 27. 2. 1962, RGANI, 5, 49, 489 (rolik 9019), Bl. 51-55.

30 Aufzeichnung des ungarischen Botschafters József Kárpáti über ein Gespräch mit Sowjetbotschafter Abrasimov am 6. 3. 1963, MOL, 288.f. 32/1963/9.ö.e., Bl. 210-212.

31 Glückwünsche der Sowjetunion, in: Neues Deutschland, 1. 1. 1963.

32 Otvety predsedatelja Soveta Ministrov SSSR N. S. Chruščëva na voprosy gazety „Dejli ekspress“, in: Pravda, 1. 1. 1963.

33 Nazrevšij vopros, in: Pravda, 6. 1. 1963. 
Der in Abstimmung mit der sowjetischen Führung vorbereitete ${ }^{34}$ VI. SED-Parteitag zeigte aller Welt, daß die Berlin- und Deutschland-Forderungen dem Kreml nicht mehr dringlich schienen. Die Parolen des Kampfes um Friedensvertrag und Freistadtregelung verschwanden aus dem Repertoire. Im einleitenden Rechenschaftsbericht am 15. Januar 1963 wiederholte Ulbricht zwar den alten Standpunkt, betonte aber die Aussicht auf Verständigung mit dem Westen und rückte die Erfordernisse von Frieden und Abrüstung in den Mittelpunkt. Statt wie früher das Ausbleiben des Separatfriedensschlusses mit der DDR zu monieren, sprach er nur von einer „verständliche[n] Ungeduld“ im Lande darüber, daß die Vorbereitung des Vertrages „so lange Zeit in Anspruch“ nehme. Die Verhandlungen mit den USA hätten jedoch schon „bestimmte Resultate gebracht.“ Demnach stand Weiteres zu erwarten; unausgesprochen bedurfte das bisherige Bemühen geduldiger Fortsetzung, um zum Einvernehmen zu führen. ${ }^{35}$

Am folgenden Tag stellte Chruschtschow den Delegierten die - schon vom SED-Chef angedeuteten - politischen Erfolge der DDR vor Augen. Sie habe die Möglichkeit gewonnen, ihre Souveränität „wirksam zu behaupten“. Die Grenze zu West-Berlin sei kein offenes Tor mehr, das subversive Kräfte ungehindert und ungestraft mißbrauchen könnten, um unter anderem „die Grundlagen des Sozialismus zu erschüttern“. Sie unterliege nunmehr der Kontrolle der DDR; das sei der „wichtigste Schritt zu Festigung der Souveränität der Deutschen Demokratischen Republik“. Am 13. August 1961 habe man auch ohne Friedensvertrag alles Notwendige erreicht. Die Grenze sei geschlossen; dem Westen werde der Zutritt verwehrt. Die DDR habe zugleich die Fähigkeit gewonnen, auf die Verkehrsverbindungen West-Berlins zur Außenwelt Druck auszuüben und diesen je nach Bedarf zu verstärken oder abzuschwächen. ${ }^{36}$ Den Äußerungen lag ein verändertes Konzept zugrunde, das Chruschtschow eineinhalb Wochen zuvor Ulbricht in einem langen Gepräch erläutert hatte. ${ }^{37}$ Schon im Dezember war Pjotr Abrassimow, der Botschafter Perwuchin ablöste, mit neuen Instruktionen nach Ost-Berlin geschickt worden. ${ }^{38}$

\section{Neue Überlegungen}

Aufgrund der Erfahrung während der Kuba-Krise wollte Chruschtschow der Konfrontation mit den USA künftig aus dem Weg gehen und daher die Westmächte nicht mehr herausfordern. Zugleich war er daran interessiert, drängende

34 W. Ulbricht an N. S. Chruščëv, 15. 9. 1962, SAPMO-BArch, DY 30/3288, Bl. 21 (dtr. Originaltext)/22 (russ. Übers.); N. S. Chruščëv an W. Ulbricht, 21. 9. 1962, SAPMO-BArch, DY 30/3288, Bl. 23 (dtr. Originaltext)/24 (russ. Übers.).

35 Referat von W. Ulbricht auf dem VI. Parteitag der SED (Auszug), 15. 1. 1963, in: Dokumente zur Deutschlandpolitik, a.a.O., IV, 9/1, S. 22-37 (Zitate auf S. 24f.).

36 Rede von Genossen N. S. Chruščëv auf dem VI. Parteitag der SED (Auszug), 16. 1. 1963, ebd., S. 38-46 (Zitate auf S. 42).

37 Das Gespräch hatte am 4. 1.1962 von 14.50 bis 18.00 Uhr in Chruščëvs Dienstzimmer stattgefunden (Posetiteli kremlevskogo kabineta N. S. Chruščëva, in: Istočnik, 4/2003 (64), S. 93).

38 Gespräch Chruščëvs mit P. A. Abrasimov, 14. 12. 1962 (ebd., S. 92); A. M. Filitov, Sovetskij Sojuz i „novaja vostočnaja politika“ FRG, in: Cholodnaja vojna i politika razrjadki: diskussionnye problemy, hrsg. von Institut vseobščej istorii RAN, Moskau 2003, S. 172-174. 
Probleme, vor allem im Bereich der internationalen Sicherheit, durch Verhandlungen mit Washington einer Lösung zuzuführen. Daher ließ er die Forderung fallen, daß man sich vorher über West-Berlin einigen müsse. Auch wenn Friedensvertrag und Freistadt-Regelung nicht mehr vordringlich waren und das Verlangen danach nach außen hin kaum noch artikuliert wurde, ging er von seinem Standpunkt nicht ab. Die sozialistischen Länder brauchten West-Berlin, die Westmächte dagegen nicht. Die Stadt könnte „eine Brücke des Friedens, ein Vorbild der Koexistenz von Staaten mit unterschiedlicher sozialer Ordnung werden." 39 Er faßte dabei keine Abstriche von den bisherigen Zielen ins Auge 40 und hielt daran fest, diese müßten kompromißlos weiterverfolgt werden. ${ }^{41}$ Es schien nur nicht mehr angebracht, sie hastig anzustreben. Ihre Durchsetzung sollte, wie Ulbricht erklärte, „nicht in einem Zug erfolgen“, sondern „in mehreren Etappen“ erreicht werden. Es ging mithin um eine „schrittweise Regelung bei der Umwandlung Westberlins in eine friedfertige, neutrale Freie Stadt“. 42

Bei der Verfolgung der alten Berlin-Ziele wurden „einige methodische Änderungen“ vorgesehen. Das Verhältnis zu den USA sollte entspannt werden. Wenn sich dessen Atmosphäre wandele, könnten Verhandlungen mit den Amerikanern über andere Fragen zum Erfolge führen. Der Kampf um West-Berlin dürfe sich daher nicht mehr direkt gegen die Westmächte richten. ${ }^{43}$ Chruschtschow betonte, es müsse Vertrauen entstehen. Nur auf diese Weise würden Kompromisse möglich, welche die Situation in Deutschland entschärfen könnten, wie das in Kuba bereits geschehen sei. Die "gegenwärtige unsichere und explosive Lage“, in der sich West-Berlin wegen dessen „Mißbrauchs“ als „NATO-Stützpunkt“ befinde, müsse „durch eine weitgehende Entspannung abgelöst werden“. Nach seiner Darstellung bot die „Ablösung der NATO-Truppen durch Verbände der UNO“ als „zusätzliche Garantie dafür, daß die Westberliner selbst frei ihr Leben einrichten“ könnten. Die UdSSR werde sich nicht einmischen. ${ }^{44}$

Der Nachdruck, mit dem sich der Kreml gegen die „westdeutsche Einmischung“ in die „inneren Angelegenheiten West-Berlins“ wandte, lag in der Sorge begründet, daß die Bundesrepublik, die auf Drängen der USA die materielle Hilfe an die Stadt verstärkte, auf diese Weise die aus der Abriegelung erwachsenden Nachteile ausgleichen könnte. Wenn es der Gegenseite gelang, dadurch mit den Schwierigkeiten nach dem 13. August 1961 fertigzuwerden und die innenpolitischen Grundlagen der westlichen Präsenz zu festigen, wurde die sowjetische Hoffnung zunichte, daß West-Berlin aufgrund ungelöster wirtschaftlicher und gesellschaftlicher Probleme zur Beute werde. Nach Moskauer Einschätzung waren die Amerikaner in der Stadt zunehmend auf die Unterstützung der Bundesregie-

39 Dokumente zur Deutschlandpolitik, a.a.O., S. $43 \mathrm{f}$.

40 Ebd., S. 44 f. Vgl. Referat von W. Ulbricht auf dem VI. Parteitag der SED, 15. 1. 1963, in: Dokumente zur Deutschlandpolitik, a.a.O., IV, 9/1, S. 22-26.

41 Aussprache Chruščëvs mit Vertretern der Bevölkerung Westberlins am 18.1. 1963, 25. 1. 1963, SAPMO-BArch, DY 30/3512, Bl. 6-30.

42 Referat von W. Ulbricht auf dem VI. Parteitag der SED, 15. 1. 1963, in: Dokumente zur Deutschlandpolitik, a.a.O., IV, 9/2, S. $24 \mathrm{f}$.

43 Politische Abteilung: Kurseinschätzung der Deutschlandpolitik der Sowjetunion 1959-1964 [hier für die „Periode ab Ende 1962“], Moskau 27. 4. 1964, PA-MfAA, A-276, Bl. $188 \mathrm{f}$.

44 Aussprache Chruščëvs mit Vertretern der Bevölkerung Westberlins am 18.1.1963 in der Wiedergabe für die Öffentlichkeit in: Neues Deutschland, 23.1. 1963. 
rung angewiesen, die daher ihre dortigen Positionen „immer schamloser“ ausbauen konnte. Es galt daher, weitere Erfolge Bonns bei der Durchsetzung seiner „illegitimen“ Ansprüche auf West-Berlin unbedingt zu verhindern. Die Entwicklung sei schon so weit fortgeschritten, daß die Stadt faktisch ein „konstituierender Bestandteil“ (sostavnaja čast') der Bundesrepublik geworden sei. Die dadurch heraufbeschworene Gefahr sei um so größer, als der negative Eindruck, den die Mauer hervorgerufen habe, die Geheimdienst- und Propagandatätigkeit der Westmächte in West-Berlin außerordentlich begünstige. Als besonderes Übel galten die von dort ausgestrahlten Rundfunk- und Fernsehsendungen. ${ }^{45}$

Die Tatsache, daß die Westmächte die Zugehörigkeit der Stadt zur Bundesrepublik durch ihr Veto verhinderten, war demnach ohne Bedeutung. Das sei ein bloß formaler Einspruch; faktisch werde die umfassende Einbeziehung in das Wirtschafts-, Finanz-, Rechts-, Vertrags- und Politiksystem der Bundesrepublik gefördert. Diese seit seit 1961 sehr verstärkt worden. Zugrunde liege eine von der NATO beschlossene Aufgabenteilung: Die Bundesrepublik sei zu wirtschaftlicher und finanzieller Hilfe verpflichtet worden, während die Westmächte die Verantwortung für den militärischen Schutz, vor allem für den Erhalt der politischen Ordnung und die Sicherung der Verbindungswege, übernommen hätten. ${ }^{46} \mathrm{Im}$ Kreml ging man davon aus, daß die von der Bundesrepublik aufgrund der bestehenden Bindungen geleistete Unterstützung für das Überleben West-Berlins unerläßlich war. Wurde sie beendet, brach die innerstädtische Basis für die Präsenz der Westmächte weg, die sich dann nicht weiter aufrechterhalten lasse. ${ }^{47}$

\section{Ein verändertes Konzept des Kampfes um West-Berlin}

Die Erkenntnis, daß der Kampf gegen die Bindungen West-Berlins an die Bundesrepublik geeignet war, die westliche Position insgesamt zu untergraben, ließ ein indirektes Vorgehen gegen diese ratsam erscheinen. Demnach hatten sich UdSSR und DDR bloß gegen für rechtswidrig erklärte westdeutsche Kompetenzanmaßungen zu wenden, die sich vorgeblich nicht nur gegen ihre Interessen, sondern auch gegen die westlichen Besatzungsrechte richteten. Tatsächlich jedoch ging es wesentlich darum, die Westmächte zu treffen. Deren Präsenz blieb nur scheinbar unbehelligt, als der „Mißbrauch Westberlins durch die westdeutschen Militaristen und Revanchisten“ zum Ziel der sowjetischen Angriffe wurde.48 Den Worten Chruschtschows gegenüber Adenauer zufolge hatte die Bundesrepublik „nicht das geringste Recht auf Westberlin“.49 Das Ziel, diesem die westdeutsche Unter-

45 P. Abrasimov an A. A. Gromyko, 28. 6. 1963, AVPRF, 0742, 2, 61, 23, Bl. 96-105. Zur Frage der Rundfunk- und Fernsehtätigkeit siehe auch Ju. Žarov/S. Semaško, O propagande GDR po radio, televideniju i pečati na Zapadnyj Berlin, 27. 4. 1963, AVPRF, 0742, 8, 61, 22, Bl. 131.

46 V. Bykov, Vključenie Zapadnogo Berlina v meždunarodnye dogovory i soglašenija FRG (spravka), 17. 4. 1963, AVPRF, 0742 , 8, 26, 15, Bl. 18-90.

47 Vgl. I. Kabin an das ZK der KPdSU, 27. 2. 1962, RGANI, 5, 49, 489 (rolik 9019), Bl. 54f.

48 Politische Abteilung: Kurseinschätzung der Deutschlandpolitik der Sowjetunion 1959-1964 [hier für die „Periode ab Ende 1962“], Moskau 27. 4. 1964, PA-MfAA, A-276, Bl. 188 f.

49 N. S. Chruščëv an K. Adenauer, 24. 12. 1962, in: Dokumente zur Deutschlandpolitik, a.a.O., IV, 
stützung zu entziehen, sollte durch Propaganda, Zermürbung und Druck erreicht werden. Erst wenn das gelungen war, wollte der Kreml wieder in Verhandlungen über Berlin eintreten. Vorher erschienen diese nutzlos, weil das das angestrebte Ergebnis, die Durchsetzung des behaupteten Status einer „Freien Stadt“ oder einer „selbständigen politischen Einheit“, wie es meist hieß, nicht zu erwarten war. Das sowjetische Desinteresse an Verhandlungen wurde mit dem Hinweis kaschiert, das Interesse an deren Fortführung liege allein bei den Amerikanern. Es sei an ihnen, neue Vorschläge zu unterbreiten. 50

Dem neuen Botschafter der UdSSR in der DDR, Abrassimow, wurde vom Kreml die - bis dahin abgelehnte - Funktion eines Hochkommissars zugewiesen. Damit erkannte die Moskauer Führung die Vier-Mächte-Rechte prinzipiell an, deren Bestehen sie seit November 1958 in Abrede gestellt hatte. Sie sollten sich jedoch nicht mehr auf Gesamt-Berlin, sondern nur noch auf die Westsektoren erstrecken. Demnach nahm der sowjetische Hochkommissar Aufgaben nur gegenüber dem Westteil der Stadt wahr, während deren östlicher Teil voll und ganz zur DDR gehörte. Zwar widersprach der damit erhobene Anspruch der UdSSR auf die Rolle einer vierten Besatzungsmacht in West-Berlin dem westlichen Standpunkt, doch hatten sich die Auffassungen insoweit angenähert, als Präsenz und Zugang der Westmächte wieder als rechtlich begründet galten und die Forderung der DDR nach unbeschränkter Souveränität auf den Transitstrecken keine Unterstützung mehr fand. Auch dem Bemühen Ulbrichts, in die Kontrolle der UdSSR über das Vorgehen gegenüber dem Westen eigenmächtig einzugreifen, wurde die Rechtfertigung entzogen. Die Westmächte sahen sich nicht mehr offen herausgefordert durch das Verlangen, ihre Berlin-Kompetenzen müßten auf die DDR übergehen. Das sowjetische Verlangen nach Teilhabe an den westlichen Befugnissen in West-Berlin blieb dagegen unausgesprochen. Die These, die „Einmischungen“ der Bundesrepublik in die inneren Angelegenheiten der Stadt verletze nicht nur deren Status und die östlichen Interessen, sondern auch die westlichen Besatzungsrechte, war darauf abgestellt, eine gemeinsame Abwehr der vier Siegermächte gegen angebliche Kompetenzanmaßungen Bonns notwendig erscheinen $\mathrm{zu}$ lassen. 51

Die neue Position entsprach ungefähr den Vorschlägen, die das Moskauer Außenministerium im November 1958 ausgearbeitet, aber damals bei Chruschtschow nicht zur Geltung bringen konnte. Einen Vorgeschmack hatte die sowjeti-

8/2, S. 1505-1509. Vgl. Antworten von N. S. Chruščëv auf Fragen der Zeitung „Daily Express“ (Auszug), 31. 12. 1962, ebd., S. $1521 \mathrm{f}$.

50 Vermerk Dr. Herder über Gespräch Abrasimov - Winzer, 18. 2. 1963, PA-MfAA, G-A 478, Bl. 8896/G-A 510, Bl. 3-11; O. Winzer an W. Ulbricht (mit Anlage), 27. 2. 1963, SAPMO-BArch, DY 30/3512, Bl. 31-40.

51 A. M. Filitov, a.a.O., S. 172-174 (unter Hinweis auf sowjetische Akten). Die detaillierteste Darstellung des neuen sowjetischen Rechtsstandpunkts findet sich bei V. N. Vysockij, Zapadnyj Berlin i ego mesto v sisteme sovremennych meždunarodnych otnošenij, Moskau 1971. Unter dem Pseudonym V. N. Vysockij verbirgt sich V. N. Beleckij, der in den sechziger Jahren in der Ost-Berliner Botschaft der UdSSR tätig war. Das Buch ist nach Ausweis des Autoreferats vom 1. 7. 1968 als Habilitationsschrift beim Institut für internationale Beziehungen an der Akademie für Staats- und Rechtswissenschaften „Walter Ulbricht“ beim ZK der SED entstanden und wurde u.a. von Botschafter Abrasimov und maßgebenden Funktionären des sowjetischen Außenministeriums gegengelesen. 
sche Anregung in den Gesprächen mit den USA von 1962 geboten, man könne vielleicht eine vierseitige Besetzung West-Berlins ins Auge fassen. Dabei war freilich nur an eine zeitlich befristete Regelung gedacht worden, die nicht mit der Ausübung von Besatzungsrechten verbunden sein sollte. Auffallend war, daß der Kreml den Positionswechsel stillschweigend vollzog, also anders als bei früheren Gelegenheiten darauf verzichtete, gegenüber den Regierungen und der Öffentlichkeit im Westen das gezeigte Entgegenkommen herauszustellen. Fürchtete Chruschtschow, Gesicht zu verlieren, wenn er nicht länger auf Forderungen bestand, deren Unwiderruflichkeit er laut verkündet hatte? Die Westmächte waren darauf angewiesen, aus sich mehrenden Hinweisen und Vorgängen ihre Schlüsse zu ziehen. Bis sich die Mosaiksteinchen zu einem Bild zusammenfügten, verging viel Zeit. Noch lange bestand daher im Westen keine Klarheit darüber, mit welcher Politik man auf der anderen Seite zu rechnen hatte. Einschlägige offiziöse Publikationen der UdSSR erschienen erst ab Mitte der sechziger Jahre. Die einzige zeitnahe Veröffentlichung war ein in Moskau verfaßter Aufsatz in der Maiausgabe einer ostdeutschen Zeitschrift, mit dem die DDR die Übernahme der sowjetischen Position bekunden mußte. Dieser Zusammenhang blieb freilich nach außen hin verborgen. 52

\section{Politische Leitlinien aufgrund des veränderten Konzepts}

Der Kreml veränderte die Ost-West-Auseinandersetzung in dreifacher Hinsicht. Erstens legte er fest, daß die DDR im Blick auf West-Berlin dem Besatzungsrecht und damit sowjetischer Kontrolle unterlag. Zweitens besaßen die Westmächte demnach keine Rechte in Ost-Berlin und konnten daher weder gegenüber der ostdeutschen Seite Anspruch auf Zutritt erheben noch bei der UdSSR einen solchen einfordern. Drittens beanspruchte Moskau ein Veto bezüglich der westlichen Entscheidungen über West-Berlin. Die sich daraus ergebende Folgerung, den Westmächten fehle die erforderliche Autorisationskompetenz, bildete die unausgesprochene Grundlage für die These, daß die Bindungen an die Bundesrepublik trotz ausdrücklicher westlicher Genehmigung rechtswidrig seien, denn sie hätten sowjetischer Zustimmung bedurft. Die UdSSR bestand auf dem Status einer von der Bundesrepublik völlig getrennten „selbständigen politischen Einheit“.53 Diese sollte ein „in Entwicklung begriffener Staat“ sein, der zwar noch unter Besatzungsrecht stand, aber sich bei Erreichen der vollen Staatlichkeit davon emanzipieren werde. Damit sollte dann die Basis für Präsenz und Zugang der West-

52 Die Deutschen und ihr Selbstbestimmungsrecht, in: Deutsche Außenpolitik, 5/1963, S. 355-365. Der mit drei Sternchen als offiziös gekennzeichnete Artikel wurde nach der auf sowjetischen Akten beruhenden Feststellung von A. M. Filitov. a.a.O., S. 172, durch Botschafter Abrasimov plaziert.

53 Erklärung der Regierung der UdSSR, 4. 9. 1963, in: Dokumente zur Deutschlandpolitik, IV 9, S. 667 f.; Ju. Višnjakov an I. I. Il’ičëv, 6. 9. 1963, AVPRF, 0742, 8, 61, 24, Bl. 15; Beseda tov. Chruščëva s učastnikami Tret'ej Vsemirnoj vstreči žurnalistov, in: Pravda, 27. 10. 1963. Chruščëv hatte schon in einer Rede vom 2.7. 1963 davon gesprochen, daß West-Berlin „kein Teil Westdeutschlands“ sei (Dokumente zur Deutschlandpolitik, IV 9, S. 499). 
mächte entfallen. Für den Zivilverkehr auf den Transitstrecken wurde eine bereits aktuell bestehende Zuständigkeit der DDR behauptet. ${ }^{54}$

Mit der These, daß die Bindungen West-Berlins an die Bundesrepublik ohne Rechtsgrundlage und damit illegal seien, stellte die sowjetische Führung unausgesprochen die Legitimität des westlichen Besatzungsregimes in Abrede. Den von westdeutscher Seite ausgeübten Befugnissen in der Stadt lagen Ermächtigungen durch die Westmächte zugrunde. Die Rechtmäßigkeit dieser Befugnisse zu bestreiten, war daher gleichbedeutend mit der Bestreitung der Rechtmäßigkeit der Ermächtigungen, auf denen sie beruhten. Wenn demnach die Westmächte nicht berechtigt waren, die Bundesrepublik zur Wahrnahme von Funktionen in WestBerlin zu ermächtigen, bedeutete dies, daß sie nicht im Besitz der dazu nötigen besatzungsrechtlichen Kompetenz waren. Den Argumenten des Kreml war zu entnehmen, daß diese nur durch das Einverständnis der UdSSR als der vierten Besatzungsmacht hätte hergestellt werden können. Diese Konsequenz der sowjetischen Rechtsposition schlug sich in den Aussagen der Moskauer Führung nicht aktuell nieder. Allem Anschein nach sollte davon erst dann die Rede sein, wenn dem Westen in künftigen Verhandlungen die politische Rechnung präsentiert wurde.

Vorerst richtete sich die sowjetische Politik vorgeblich nur gegen die Ambitionen Bonns. Der Kreml war sichtlich bemüht, jeden Hinweis auf eine Infragestellung der westlichen Position zu vermeiden. Chruschtschow verzichtete darauf, die Aufhebung des Besatzungsrechts für irgendwann zu fordern. Die UdSSR werde ihren Standpunkt erst bei Abschluß des Friedensvertrags geltend machen. Er sicherte den Westmächten sogar zu, daß er ihre Truppenpräsenz „unangetastet lassen“ wolle, wenn sie dann an der Friedensregelung nicht mitwirken würden und damit die Chance versäumten, auf deren Gestaltung Einfluß zu nehmen. Das hieß freilich nicht, daß er bereit war, ihnen dann die weitere Ausübung der Besatzungsrechte zuzugestehen. Die Okkupation sollte durch den Friedensvertrag beendet werden. Dabei werde der DDR sollte „lediglich“ die Zuständigkeit für den - propagandistisch als „freien Transit“ bezeichneten - Zivilverkehr übertragen werden. Die westlichen Militärkonvois könnten ihre Fahrten ungestört fortsetzen. ${ }^{55}$ Das war ein nur scheinbares Entgegenkommen. Wenn es kein westliches Besatzungsregime mehr gab und die Verbindungen West-Berlins zur Außenwelt in aller Form dem SED-Regime überantwortet waren, verloren die Westmächte ihre Befugnis zum Schutz der Stadt vor östlicher Einwirkung.

Nach sowjetischer Darstellung war die Umwandlung West-Berlins in eine „selbständige politische Einheit“ notwendig, um der angeblichen Fremdbestimmung durch die Bundesrepublik ein Ende zu machen. ${ }^{56}$ Als daraufhin von westli-

54 Juri Rschewski [Jurij Rževskij], Westberlin - ein Gebilde sui generis. Moskau o.D. [1966/67].

55 Aussprache Chruščëvs mit Vertretern der Bevölkerung Westberlins am 18.1. 1963, 25. 1. 1963, SAPMO-BArch, DY 30/3512, Bl. 18f.; Osnovnoe položenie o svobodnom tranzite graždanskich lic i gruzov v Vol'nyj gorod Zapadnyj Berlin i iz nego po territorii GDR [Entwurf], 7. 1. 1963, AVPRF, 0742, 8, 59, 4, Bl. 17-20.

56 Vgl. N. S. Chruščëv an J. F. Kennedy, o.D. [Ende April/Anfang Mai 1963], in: FRUS 1961-1963, VI, S. 271-279; N. S. Chruščëv an J. F. Kennedy, 8. 5. 1963, ebd., S. 279-286; Message From the Soviet Ministry of Foreign Affairs to the Soviet Ambassador to the United States (Dobrynin), 1. 4. 1963, ebd., S. 250-262; Telegram From the Embassy in the Soviet Union to the Department of State [über Gespräch Chruščëv - Harriman], 27. 7. 1963, in: FRUS 1961-1963, XV, S. 539-544; 
cher Seite angeregt wurde, die geforderte Selbstbestimmung dadurch zu verwirklichen, daß man die Bevölkerung darüber abstimmen lasse, ob sie die Umwandlung ihrer Stadt in eine „selbständige politische Einheit“ wolle, lehnte man in Moskau ab. Der Status sei „kein selbständiges, isoliertes Problem, sondern ein untrennbarer Teil der Frage der deutschen Friedensregelung ", für welche die Staaten der Anti-Hitler-Koalition, vor allem die Unterzeichner der Vier-Mächte-Abkommen, die Verantwortung trügen. Thre „Rechte in den Fragen, die Deutschland als Ganzes betreffen“, hätten „die Verpflichtung“ zum Inhalt, „die Vorbereitung und den Abschluß eines Friedensvertrages zu beenden und auf dieser Grundlage die Frage Westberlins zu lösen“, das „zu einer eigenartigen politischen Anomalie inmitten der DDR geworden" sei und „auf deren Territorium“ liege. Erst wenn man das Besatzungsregime in der Stadt beseitigt und den völkerrechtlichen Status auf der Grundlage des Friedensvertrages festgelegt habe, seien die Bewohner in die Lage versetzt, ,alle inneren und auch alle - im Rahmen des für Westberlin festgelegten Status - äußeren Angelegenheiten selbst, ohne irgendwelche äußeren Einmischungen zu entscheiden. " 57

Der Kreml war zwar von der Linie offener Konfrontation abgerückt, doch bildete die Forderung nach „Beseitigung der Überreste des Krieges“ und nach „Normalisierung der Lage in West-Berlin" weiterhin den Kern seiner Rechtsposition. Das war für die Westmächte unannehmbar. Gleichwohl bestand ein wesentlicher Unterschied zu der Haltung, die er vor der Kuba-Krise eingenommen hatte. Er stellte sich zusammen mit den drei westlichen Regierungen auf den Standpunkt, daß die Vier-Mächte-Rechte bis auf weiteres gültig seien und daher nicht in Frage gestellt werden sollten. Auch wenn deren Inhalt strittig war, entstand damit eine grundlegende Gemeinsamkeit: Der DDR wurde von beiden Seiten das Recht zur Übernahme westlicher Berlin-Kompetenzen abgesprochen. Das galt, auch wenn nach sowjetischer Vorstellung davon bei Abschluß des Friedensvertrages abgegangen werden sollte. Da hierfür kein Termin ins Auge gefaßt wurde, war dieser Vorbehalt für die aktuelle Situation ohne Bedeutung. Die erneute Anerkennung der Vier-Mächte-Rechte setzte den Rahmen für die Verhandlungen zwischen der UdSSR und den Westmächten Anfang der siebziger Jahre. Der Dissens, ob sich die aus der Besatzungszeit überkommenen Rechte auf (Gesamt-)Berlin oder auf West-Berlin bezögen, wurde zur Grundlage eines Modus vivendi. Im VierMächte-Abkommen vom 3. September 1971 gestanden sich die Verhandlungspartner wechselseitig unterschiedliche Grundsatzpositionen zu und verständigten sich zugleich auf Verfahren, wie die daraus erwachsenden Konfliktsituationen einvernehmlich geregelt werden sollten. Das wäre nicht möglich gewesen, wenn der Kreml unter Leugnung der Vier-Mächte-Rechte weiter an den Forderungen vom November 1958 festgehalten hätte.

Aufzeichnung aus Moskau [ohne Überschrift], 12. 6. 1963, SAPMO-BArch, DY 30/3663, Bl. 199205.

57 Die Deutschen und ihr Selbstbestimmungsrecht, a.a.O., S. $361 \mathrm{f}$. 


\section{Differenzen mit der SED-Führung}

Das erneute sowjetische Bekenntnis zu Vier-Mächte-Rechten frustrierte die SEDFührung. Der Abschluß des Friedensvertrages mit folgender Kontrolle über die Zugangswege West-Berlins war auf unbestimmte Zeit vertagt, und die DDR sah sich von der UdSSR langfristig unter Vier-Mächte-Recht gestellt, auch wenn ihr Ost-Berlin voll zugesprochen wurde. Das zog gravierende Konsequenzen für das Verhältnis zur Hegemonialmacht nach sich. Die Sowjetunion konnte nicht mehr nur zeitweise bis zur baldigen Entscheidung des Konflikts mit den Westmächten, sondern auf lange Dauer und mit voller Legitimität fordern, daß die DDR Einschränkungen ihrer Souveränität akzeptierte. Das erschien als unerträgliche Zumutung, doch konnte man keinen Angriff auf die sowjetische Grundsatzposition wagen. Ulbricht suchte daher mit kleinen Schritten voranzukommen.

Den Anfang machte er mit dem Verlangen nach Aufhebung von Formalien, die mit Vier-Mächte-Rechten zusammenhingen. Als geeigneter Ort dafür erschien ihm Ost-Berlin, wo es ja auch nach sowjetischer Ansicht keine vierseitigem Zuständigkeiten mehr gab. Dessen ungeachtet, nahm die Bevölkerung dort nach wie vor nicht an den DDR-Wahlen teil. Analog zur Praxis in West-Berlin entsandte die Stadtversammlung „Vertreter“ in die Volkskammer, die dort kein Stimmrecht hatten. Das war zwar ohne praktische Bedeutung, weil politische Unterschiede nicht zugelassen waren, doch wurmte den SED-Chef die darin zum Ausdruck kommende Statusdifferenz zwischen der DDR und ihrer Hauptstadt. Der Kreml lehnte jedoch ab. Die „deutschen Freunde“ hätten nicht alle eventuellen Folgen bedacht. Zwar sei verständlich, daß sie die Autorität der DDR-Regierung durch eine Beteiligung der Ost-Berliner an den Volkskammerwahlen stärken wollten. Dagegen sei an sich nichts einzuwenden, denn eine Aufhebung des Sonderstatus berühre weder die Verbindungen zwischen West-Berlin und der Bundesrepublik noch den Status West-Berlins (also die beiden Probleme, die sich die UdSSR vorbehalten hatte). Es seien aber die Resonanz und die möglichen Reaktionen des Auslands zu berücksichtigen. Wenn die Rechtslage Ost-Berlins verändert werde, könne dies den Westmächten als Vorwand für eine weitere Verstärkung der Bindungen West-Berlins an die Bundesrepublik und für die Schaffung zusätzlicher Hindernisse gegen dessen Umwandlung in eine Freie entmilitarisierte Stadt dienen. Es sei nicht auszuschließen, daß dann sogar die förmliche Eingliederung der Stadt in den westdeutschen Staat auf die Tagesordnung gesetzt werde. Den DDRFührern wurde empfohlen, nicht einseitig vorzugehen und die Sache in Konsultationen mit der UdSSR zu klären. ${ }^{58}$

Am 18. Juli traf Gromyko mit einer DDR-Delegation zu einer Berlin-Besprechung zusammen. Die ostdeutschen Vertreter äußerten eingangs den Wunsch, die Beseitigung der „Überreste des Zweiten Weltkriegs“ und des Besatzungsregimes, die „Durchbrechung der Hallstein-Doktrin“ und eine darauf ausgerichtete Kampagne zu erörtern. Der Außenminister war aber nur zur Diskussion von Forderungen bereit, deren Erfüllung den Westen nicht herausforderte: eine bessere Bezahlung von Dienstleistungen der DDR für die Garnisonen in West-Berlin und

58 Botschafter Abrasimov an I. I. Il’ičëv, 15. 6. 1963, AVPRF, 0742, 2, 61, 23, Bl. 53 f. 
eine Veränderung der Modalitäten des westlichen Zutritts zum Ostteil der Stadt. Auch bei diesen vergleichsweise risikoarmen Themen bekundete Gromyko Vorsicht und Zurückhaltung. Er erklärte sich zwar mit dem Verlangen nach Tariferhöhungen grundsätzlich einverstanden, machte aber zugleich geltend, man habe zu berücksichtigen, zu welchen Gegenmaßnahmen die Westmächte gegebenenfalls greifen könnten. Er äußerte Verständnis für die Forderung, daß die nach OstBerlin einreisenden westlichen Militärangehörigen ihre Ausweise vorzeigen und der DDR-Gerichtsbarkeit unterstehen sollten, und sprach sich dafür aus, ihre Bewegungsfreiheit „in bestimmtem Maße“ einzuschränken, hielt aber vor einem abschließenden Votum „nähere Erläuterungen“ der ostdeutschen Antragsteller für erforderlich.

Der Außenminister ließ keinen Zweifel daran, daß eine Einschränkung der Vier-Mächte-Kompetenzen nicht in Betracht komme, wenn davon negative Rückwirkungen für die UdSSR zu befürchten waren. Mit der Begründung, die Warschauer-Pakt-Staaten würden bei wechselseitiger Aufhebung insgesamt „mehr verlieren als gewinnen“, wies er das Verlangen zurück, die Tätigkeit der westlichen Militärmissionen in Potsdam zu beenden. Er bestand auch darauf, daß die Abfertigung der Truppenkonvois der Westmächte auf den Transitstrecken ausschließlich Sache der Sowjetunion sei. Er gestand der DDR lediglich zu, daß sie in ihrer Hauptstadt ihre Gerichtshoheit auch gegenüber westlichen Amtspersonen ausüben könne. Zur „Vermeidung von Komplikationen“ sah er aber vor, die ostdeutschen Behörden müßten sich dann mit der UdSSR abstimmen. Auf den Wunsch nach Beschränkung der westlichen Patrouillenfahrten durch Ost-Berlin ging Gromyko mit dem Hinweis ein, man könne eine „massenhafte Einreise“ westlicher Garnisonsmitglieder vielleicht durch ein Verbot von Militärbussen verhindern. Als weiteres Zugeständnis, das keinen Konflikt mit den Westmächten hervorrufen würde, akzeptierte er die Anwesenheit von Vertretern ostdeutscher Sicherheitstruppen an den von den Militärkonvois benutzten Übergangsstellen Marienborn und Nowawes, soweit diese dabei nicht mit den westlichen Soldaten in Kontakt kamen. Der diensthabende sowjetische Offizier, der die Begleitpapiere weiter entgegennahm, registrierte, prüfte und zurückgab, sollte diese zwischendurch den DDR-Vertretern im Hintergrund zur Einsicht und eventuellen Registrierung aushändigen. ${ }^{59}$

Wie klein der Entscheidungsspielraum war, den der Kreml der SED-Führung ließ, zeigte sich bei Ulbrichts Vorschlag, die „Reichsbahn“ umzubenennen. Während die Bundesrepublik längst die Bezeichnung „Deutsche Bundesbahn“ eingeführt hatte, galt in der DDR nach wie vor das Etikett der Vorkriegszeit. Die sowjetische Seite teilte zwar die Ansicht, daß dieses nicht mehr angebracht war,

59 Aktenvermerk über die 1. Konsultation am 18. 7. 1963 im [Moskauer] Ministerium für Auswärtige Angelegenheiten, SAPMO-BArch, DY 30/3512, Bl. 267-274; Erwägungen, die während der Konsultation zum Ausdruck gebracht wurden, o.D. [18. 7. 1963], SAPMO-BArch, DY 30/3512, B1. 281-291; Aktenvermerk über die gemeinsame Beratung der [ost]deutschen und der sowjetischen Delegation zu den Moskauer Konsultationen am 18.7. 1963, SAPMO-BArch, DY 30/3512, Bl. 292-326; Anlage zum Aktenvermerk über die Beratung der Arbeitsgruppe am 18.7. 1963, SAPMO-BArch, DY 30/3512, B1. 327f.; Aktenvermerk über die zweite Vollsitzung der Delegationen der UdSSR und der DDR am 19. 7. 1963 im Außenministerium der UdSSR, SAPMO-BArch, DY 30/3512, Bl. 329-331. 
fürchtete aber, daß eine Bezugnahme auf den Namen des neuen Staates negative Folgen nach sich ziehen würde, weil die Völkergemeinschaft diesem nach wie vor die Anerkennung verweigere. Die Teilnahme der ostdeutschen Bahn an den internationalen Verkehrsvereinbarungen könnte dadurch gefährdet werden. Auch bestehe das Risiko, daß ihr dann unter Hinweis auf den Standpunkt Bonns, die Bundesrepublik habe die Rechtsnachfolge des Reiches angetreten, das von dessen Bahn überkommene Erbe in West-Berlin streitig gemacht werde. Dem SED-Regime wurde empfohlen, lieber an eine „neutrale Bezeichnung für die Eisenbahnen der DDR“ zu denken. ${ }^{\circ 0}$ Das Ergebnis war, daß der alte Name blieb.

\section{Sowjetisch-amerikanische Gespräche ohne Bewegung}

Am 18. Januar 1962 fragte Botschafter Kohler vor der Abreise nach Washington bei Gromyko an, ob er ihm eine Mitteilung mitzugeben habe. Der Außenminister erwiderte, er wolle den Standpunkt seiner Regierung nicht nochmals wiederholen, aber zum Ausdruck bringen, daß diese ihre Vorschläge als eine gute, allen Seiten gerecht werdende Grundlage für eine Übereinkunft ansehe. Der Friedensvertrag sei nach wie vor aktuell und vorrangig. Man habe dafür keinen Termin gesetzt. Die USA und ihre Verbündeten würden aber einen großen Fehler machen, wenn sie daraufhin meinten, die Sache sei nicht mehr dringlich. Eine Fortsetzung der Gespräche sei wünschenswert.61 Das war eine ungewöhnlich schwache Betonung des sowjetischen Interesses, zumal jede Andeutung einer Nuance unterblieb, die den Amerikanern vielleicht einen Anreiz zum Dialog gegeben hätte. Intern hieß es Mitte Februar sogar, es seien zwar neue amerikanische Vorschläge zu erwarten, doch beabsichtige man derzeit keine weiteren Gespräche mit den Vereinigten Staaten. ${ }^{62}$

Nachdem Thompson wieder nach Moskau zurückgekehrt war, ließ ihn Gromyko - neben einem Protest gegen das Ölleitungsröhrenembargo der NATO das Interesse der UdSSR an weiteren Gesprächen über Friedensvertrag und Berlin-Regelung wissen. ${ }^{63}$ Obwohl erneut jeder Hinweis auf eine Minderung der sowjetischen Forderungen fehlte, sah Kohler darin die ernsthafteste sowjetische Bekundung des Willens zur Lösung des Problems seit dem Ultimatum von 1958.64 Kennedy scheint gleicher Ansicht gewesen zu sein. Er äußerte nachdrückliches Bedauern darüber, daß sich Bonn und Paris, ungeachtet des Angebots aus Moskau, gegen weitere Sondierungen stellten, und erwog, die Gespräche ohne Konsens mit den Verbündeten fortzuführen und dies der Gegenseite auch offen zu sagen. Nach Einwänden seiner Mitarbeiter schob er die Explorationen bis zur

60 Gespräch V. S. Semënov - W. Ulbricht, 26. 7.1963 (mit Anlage), AVPRF, 29. 7. 1963, AVPRF, 0742, 8, 59, 4, Bl. 8-11.

61 Telegram From the Embassy in the Soviet Union to the Department of State, 18. 1. 1963, FRUS 1961-1963, XV, S. $478 \mathrm{f}$.

62 Vermerk über Aussprache zwischen Botschafter Abrasimov und StS Winzer, 18. 2. 1963, SAPMOBSArch, DY 30/30/3512, Bl. 32.

63 Telegram From the Embassy in the Soviet Union to the Department of State, 26.1. 1963, ebd., S. $480 \mathrm{f}$.

64 Ebd., S. 482, Fußnote 1. 
erhofften Einigung mit den Westdeutschen auf, denen er freilich das amerikanische Interesse nachdrücklich vor Augen stellen wollte. ${ }^{65}$

Am 25. Februar erklärte sich Kohler in Moskau zu weiteren Unterredungen bereit. Gromyko zeigte sich erfreut und meinte, wenn es der anderen Seite damit ernst sei, lasse sich eine Verständigung aufgrund der sowjetischen Vorschläge erzielen.66 Der erste Gedankenaustausch kam nach einiger Verzögerung am 26. März zustande. Gegenüber Rusk wiederholte Dobrynin die - von den Amerikanern nie akzeptierte - Erklärung, man sei sich, abgesehen von der Truppenpräsenz in West-Berlin, über alles einig geworden. Aufgrund einer beiläufigen Äußerung Chruschtschows vom Ende des Vorjahres schlug er vor, die Westmächte könnten während einer noch festzulegenden Übergangszeit Kräfte in der Stadt behalten, wenn die UNO statt der NATO den Rahmen bilde. Die USA hätten sich dazu noch nicht geäußert, obwohl der Vorschlag eine gute Grundlage für die Lösung dieser höchst schwierigen Frage sei und den Weg zur Umwandlung WestBerlins in eine freie, entmilitarisierte Stadt freimache. Rusk bestand demgegenüber auf dem Anwesenheitsrecht der Westmächte und wies auf andere kontroverse Punkte hin, vor allem auf die strittigen Zugangsmodalitäten. Von einer Übereinkunft blieb man so weit entfernt wie nur jemals. Man wollte aber den begonnenen Dialog fortführen. ${ }^{67}$

Der sowjetische Vorschlag, für eine gewisse Frist die westliche Anwesenheit in West-Berlin unter UNO-Flagge zu vereinbaren, wurde an Bedingungen geknüpft. Erstens sollte jeder Hinweis auf das Bestehen einer besatzungsrechtlichen Gewalt beseitigt werden. Der Stadt war ein völlig neuer Status als „selbständige politische Einheit" zuzuerkennen, ohne daß die Vereinten Nationen ein Mandat für deren Angelegenheiten erhielten. Zweitens wurde verlangt, daß die vier Siegerstaaten diesen Status durch einen Garantievertrag bekräftigten, dem beizutreten die UNO aufgefordert werden sollte. Drittens hatten die Vier Mächte und die Weltorganisation zu vereinbaren, daß die westliche Präsenz in West-Berlin kein Recht zur Ausübung von Macht einschloß. Die Truppen dürften sich nicht in die inneren Angelegenheiten der Stadt einmischen; bei Statusverletzungen sollte der Sicherheitsrat tätig werden. Dieser sollte auch die Einheiten für West-Berlin beschließen und kontrollieren. ${ }^{68} \mathrm{Da}$ die UdSSR in dem Gremium ein Veto hatte, lief die Regelung darauf hinaus, daß selbst die minimalen Rechte, die der UNO zugedacht waren, nur mit sowjetischem Einverständnis auszuüben sein würden.

An der Unvereinbarkeit der beiderseitigen Standpunkte änderte sich auch in den folgenden Gesprächen nichts. ${ }^{69}$ Besonders aufschlußreich sind Äußerungen Chruschtschows gegenüber Averell Harriman vom 26. April. Der Kremlchef

65 Memorandum of Conversation [Kennedy mit Rusk u.a. außenpolitischen Beratern], 15. 2. 1963, ebd., S. 486-488.

66 Telegram From the Embassy in the Soviet Union to the Department of State, 25. 2. 1963, ebd., S. $491 \mathrm{f}$.

67 Memorandum of Conversation, 26. 3. 1963, ebd., S. 497-504.

68 3. Europäische Abteilung [des sowj. Außenministeriums], K voprosu o zamene flaga NATO v Zapadnom Berline flagom OON, 31.3. 1963, AVPRF, 0742, 8, 61, 22, Bl. 119-121.

${ }_{69}$ Memorandum of Conversation [Rusk - Dobrynin], 12. 4. 1963, ebd., S. 506-509; Telegram From the Embassy in the Soviet Union to the Department of State [über Gespräch Kohler - Zorin], 27. 5. 1963, ebd., S. 518f.; Telegram From the Embassy in the Soviet Union to the Department of State [über Gespräch Kohler -Zorin], 27. 5. 1963, ebd., S. 521-523. 
sprach weithin andere Fragen an, etwa das geplante Abkommen über einen Stopp der Kernwaffenversuche, und meinte hinsichtlich Berlins, die Stadt sei „nicht länger eine Quelle irgendwelcher Sorge“, denn die sozialistischen Länder hätten durch die Mauer mehr erreicht als durch einen Friedensvertrag ohne Mauerbau. Die UdSSR bemühe sich um eine Regelung nur noch mit dem Ziel, einen Beitrag zur Milderung der Spannungen zu leisten. An der bestehenden Situation würde sich nichts ändern, außer daß die beiden deutschen Staaten eine Legitimation erhielten. ${ }^{70}$ Das verminderte Interesse an der Durchsetzung der Berlin-Forderungen bedeutete kein Abrücken vom kompromißlosen Standpunkt. Vielmehr zog der sowjetische Führer die Konsequenz, daß ihm die Entlastung vom Druck, ein Ergebnis erreichen zu müssen, erst recht eine unnachgiebige Position erlaube. Zugleich erklärte er den Berlin-Konflikt für unwichtig, der ihm vorerst ohnehin keine Chance für eine Einigung zu bieten schien. ${ }^{71}$

\section{Test an den Übergangsstellen des militärischen West-Berlin-Verkehrs}

Während Kennedy vergeblich eine Verständigung über Berlin suchte, hatte Chruschtschow Erfolg mit dem Bemühen, sich mit den USA über andere Probleme zu verständigen. Am 25. Juli 1963 schloß er den Kernwaffenteststoppvertrag. Am 30. August wurde zwischen Moskau und Washington ein „heißer Draht“ eingerichtet, der bei Bedarf eine rasche Kommunikation zur Lösung akuter Konflikte ermöglichen sollte. Die amerikanische Regierung lehnte aber einen Nicht-Angriffs-Pakt zwischen NATO und Warschauer Pakt ab. Eine solche Vereinbarung würde dem Anspruch nicht gerecht werden, eine Aggression zuverlässig zu verhüten. Währenddessen gab Chruschtschow die Hoffnung auf eine Berlin-Regelung in seinem Sinne nicht auf, zumal ihn die SED-Führung bedrängte, die DDR müsse endlich die Kontrolle an den Grenzübergängen der West-Berliner Zugangswege und darüber hinaus auf der gesamten Transitautobahn erhalten. Die UdSSR müsse Druck machen und notfalls Manöver an den Luftkorridoren durchführen. ${ }^{72}$ Als Chruschtschow nach Unterzeichnung des Teststoppvertrags Harriman bei sich zu Gast hatte, fragte er während eines Federballspiels unvermittelt nach der Einstellung der USA zu Berlin. Der Diplomat wollte eine deutliche Antwort vermeiden. Unter unausgesprochener Bezugnahme auf das sowjetische Argument, ein Krieg wegen Berlins sei doch ganz unvernünftig, meinte er, sein Gastgeber müsse mit amerikanischer Unvernunft rechnen. ${ }^{73}$

Im Frühjahr und Sommer 1963 erinnerte der Kreml mehrfach daran, daß er in Berlin über Pressionsmöglichkeiten verfügte. Ab Mitte Februar wurden den USA bei der Abfertigung ihrer Militärkonvois und bei der Benutzung des Luftraums

70 Memorandum of Conversation [Chruščëv - Harriman], 26.4. 1963, ebd., S. $510 f$.

71 P. Abrasimov an A. A. Gromyko, 28. 6. 1963, AVPRF, 0742, 2, 61, 23, Bl. 96.

72 Erste Gedanken zu den Arbeitsnotizen [aufgrund der Moskauer Konsultationen], 20. 7. 1963, PAMfAA, C 848/75, Bl. 212-216; Gedankenstütze [hierzu], o.D. , PA-MfAA, C 848/75, Bl. 217.

73 Harald Biermann, John F. Kennedy und der Kalte Krieg. Die Außenpolitik der USA und die Grenzen der Glaubwürdigkeit, Paderborn 1997, S. 208 f. 
über Ost-Berlin (beim Anflug der Flughäfen im Westteil der Stadt) Schwierigkeiten gemacht. ${ }^{74} \mathrm{Da}$ es sich diesmal um relativ geringe Behinderungen handelte, hielt man in Washington keinen Protest auf Regierungsebene für nötig und ging zur Tagesordnung über. Während des Frühjahrs verschärften sich die sowjetischen Proteste gegen Aspekte der Bindungen West-Berlins an die Bundesrepublik. Im Mai verbuchte es die UdSSR als Erfolg, daß die Westmächte durch Einwände „gegen die Benutzung West-Berlins zu provokatorischen Zwecken und gegen die Durchführung von Maßnahmen der ,Zugehörigkeit West-Berlins zur BRD““ dazu bewogen worden seien, die westdeutsche Seite an der Abhaltung einer Bundestagssitzung in der Stadt zu hindern. ${ }^{75}$ Im August ging der Kreml dazu über, West-Berlin nicht mehr nur als Gebilde mit Sonderstatus, sondern ausdrücklich als „besondere politische Einheit“ zu bezeichnen, der angemessene Selbständigkeit zuzubilligen sei.

Im Herbst wurde der Druck verstärkt. Die UdSSR begann, bei der Abfertigung des westlichen Truppenverkehrs zwischen Bundesrepublik und West-Berlin Schwierigkeiten zu machen. Am 10. Oktober 1963 verlangte das sowjetische Militär von einer 25 Mann zählenden amerikanischen Kolonne bei der Einreise am Übergang Marienborn den Ausstieg aus den Fahrzeugen. Die USA hatten zwar diese Prozedur 1961 für Konvois mit mehr als 30 Soldaten akzeptiert, um die Feststellung der Personenzahl zu erleichtern. Bei kleineren Transporten war das Verfahren jedoch nie vorgesehen worden. Daher weigerte sich die Kolonne. Daraufhin wurde sie nicht durchgelassen. Kurz danach trafen zwei Mann in einem Konvoi aus West-Berlin ein, die ebenfalls zum Ausstieg aufgefordert wurden, obwohl das zuvor bei ihrer Einreise in Nowawes nicht zugemutet worden war. Auch sie waren dazu nicht bereit. Anschließend kam noch ein Militärtransport der USA mit über 30 Soldaten an, der mithin der Ausstiegspflicht zweifelsfrei unterlag. Dessen Befehlshaber verzichtete jedoch aus Solidarität mit den beiden festgehaltenen Kolonnen auf die Abfertigung und vergrößerte damit das Problem für die sowjetische Seite.

Bei dem Streit ging es nicht um die Transitprozedur, sondern um die grundsätzliche Frage, ob die UdSSR von sich aus einseitig Verfahren festlegen konnte und damit ein Recht auf Kontrolle nach eigenem Ermessen besaß. Daher wurde die Sache in Washington zum Beratungsgegenstand auf höchster Ebene. Rusk sprach den Vorfall gegenüber Dobrynin, Kennedy gegenüber Gromyko an. Dieser erklärte am 12. Oktober, seine Regierung sehe kein Problem darin, wenn man auf dem Gebiet der Rüstungskontrolle zusammenwirke und sich gleichzeitig über Berlin auseinandersetze. Am Konflikt auf den Zugangswegen gab er den amerikanischen Militärs die Schuld, fügte aber beschwichtigend hinzu, die UdSSR wolle keine Zwischenfälle bezüglich Berlins, die zu Spannungen führen könnten. Die Vorgänge sollten nicht so verstanden werden, als suche man kein gutes Verhältnis zu den USA. ${ }^{76}$

74 Telegram From the Mission in Berlin to the Department of State, 21. 2. 1963, ebd. , S. 491.

75 L. Usyčenko, O vozraženijach zapadnych deržav protiv provedenija zasedanija Bundestaga v Zapadnom Berline, 22. 5. 1963, AVPRF, 0742, 8, 26, 15, B1. 94-97.

76 Memorandum of Telephone Conversation Between Secretary of State Rusk and Foreign Minister Gromyko, 12. 10. 1963, in: FRUS 1961-1963, XV, S. 608 f. 
Währenddessen ging das Drama auf der Transitstrecke weiter. Der Chef der amerikanischen Einheit in Helmstedt erhob Einspruch beim diensthabenden Offizier der UdSSR in Marienborn und erhielt die kompromißlose Antwort, Konvois mit vier und mehr Mann sollten aussteigen. Daraufhin würden sie durchgelassen werden. Der Stadtkommandant der USA in Berlin ließ nun nach Rücksprache mit dem Oberbefehlshaber in Europa sein Gegenüber wissen, die Konvois würden ohne Abfertigung weiterfahren, falls diese nicht bis Mitternacht durchgeführt worden sei. Daraufhin errichteten sowjetische Truppen Hindernisse, die das unmöglich machten. Im Gegenzug blockierten die festgehaltenen Soldaten gemäß erteilter Weisung den Verkehr auf der Autobahn. Um diesen freizubekommen, war der Diensthabende an der Übergangsstelle fünf Minuten vor Ablauf der gesetzten Frist bereit, die Durchfahrt ohne Aussteigen zu gestatten. Als der Konvoi aber den Grenzpunkt zu West-Berlin erreichte, stand er erneut der Forderung nach Ausstieg gegenüber. Erst am Mittag des 12. Oktober - nach insgesamt annähernd 53 Stunden - sahen sich die sowjetischen Grenzbehörden durch die beharrliche Weigerung der Amerikaner zur Freigabe der Durchfahrt veranlaßt.77 Obwohl sich die Kolonne der Forderung nicht gebeugt hatte, erklärte Armeegeneral Jakubowskij in den für die SED-Führung bestimmten Berichten, diese sei durchgesetzt worden. ${ }^{78}$

Damit war der Konflikt nicht zu Ende. Die UdSSR wies amerikanische Proteste gegen das Vorgehen zurück und stellte sich auf den Standpunkt, die Soldaten der USA seien zu recht festgehalten worden, weil sie gegen die bestehende Praxis verstoßen hätten. ${ }^{79}$ Vermutlich sah sich die sowjetische Seite zu dieser unnachgiebigen Antwort dadurch ermutigt, daß unter den Westmächten keine Einmütigkeit über die Reaktion auf das Verlangen nach Ausstieg bestand. Am 16. Oktober wurde ein britischer Konvoi sechs Stunden lang aufgehalten. Diese Erfahrung ließ in London die Einsicht wachsen, daß man den Zumutungen der anderen Seite gemeinsam begegnen müsse. Es gelang den westlichen Staaten, sich auf ein einheitliches Vorgehen zu einigen. Man arbeitete zusammen Verfahrensregeln aus, die der bisherigen Praxis entsprachen, der zufolge die Untergrenze für den Ausstieg bei 30 Mann lag. Am 29. Oktober wurde das Papier dem sowjetischen Oberkommandierenden in Deutschland übergeben. ${ }^{80}$ Dieser hatte inzwischen eine neue In-

77 John C. Ausland, Kennedy, Khrushchev, and the Berlin-Cuba Crisis 1961-1964, Oslo 1996, S. 8084; Telegram From the Department of State to the Embassy in the Soviet Union, 11. 10. 1963, in: FRUS 1961-1963, XV, S. 594; Memorandum of Conference With President Kennedy (mit Anlage), 11. 10. 1963, ebd., S. 595-600; Telegram From the Embassy in the Soviet Union to the Department of State, 11. 10. 1963, ebd., S. 601; Memorandum of Conference With President Kennedy, 11. 10. 1963 , ebd., S. 602-604.

78 Armeegeneral I. Jakubovskij an W. Ulbricht, 14. 10. 1963, SAPMO-BArch, DY 30/3691, Bl. $164 \mathrm{f}$. (dte. Übers.), 166f. (russ.); Armeegeneral I. Jakubovskij an W. Ulbricht, 24. 10. 1963, SAPMOBArch, DY 30/3691, Bl. 170-172 (dte. Übers.), 173-175 (russ.).

79 Memorandum of Conversation [Thompson - Dobrynin], 11.10. 1963, ebd., S. 605 f.; Telegram From the Embassy in the Soviet Union to the Department of State, 12. 10. 1963, ebd., S. 606-608; Memorandum From the Department of State to the Mission to the North Atlantic Treaty Organization and European Regional Organizations, 15. 10.1963, ebd., S. $610 \mathrm{f}$.

80 J. C. Ausland, a.a.O., S. 84 f., 184-190; Telegram From the Department of State to the Embassy in Germany, 18. 10. 1963, in: FRUS 1961-1963, XV, S. 611-613; Memorandum From the President's Special Assistant for National Security Affairs to President Kennedy, 21. 10. 1963, ebd., S. 613 f.; Memorandum for the Record, 21. 10. 1963, ebd., S. 615; Memorandum for the Record, 25. 10. 
struktion veranlaßt, welche die militärischen Grenzbehörden auf Intransigenz festlegte. ${ }^{81}$

Am 4. November setzten die USA einen Konvoi mit 20 Soldaten nach WestBerlin in Marsch, um die Reaktion auf die innerwestlich vereinbarte Regelung zu testen. Der sowjetische Offizier in Marienborn verweigerte die Durchfahrt. Nach anfänglichem Zögern ermächtigte Kennedy die festgehaltene Einheit dazu, nach Ablauf einer bestimmten Frist weiterzufahren, falls die Abfertigung bis dahin nicht erfolgt sei. Zudem bestellte Rusk auf seine Weisung hin den Botschafter der UdSSR ein. Weil Dobrynin abwesend war, erschien sein Vertreter. Ihm erklärte der Außenminister, diesmal könne von einem Mißverständnis keine Rede sein, nachdem man die sowjetische Seite über die Verfahrensregeln unterrichtet habe. Das blieb jedoch ohne Wirkung. Daraufhin teilte der amerikanische Stadtkommandant von Berlin der anderen Seite mit ausdrücklicher Ermächtigung des Präsidenten mit, der Konvoi werde unabgefertigt weiterfahren, wenn diese Abfertigung nicht innerhalb von zwei Stunden vorgenommen worden sei. General Jakubowskij wies seine Leute an, unbedingt weiter auf dem Ausstieg zu bestehen.

Um Mitternacht setzte sich der amerikanische Militärtransport wie angekündigt in Bewegung, sah aber den Weg von bewaffneten Mannschaftswagen verstellt. Daher machte er am Grenzübergang halt. Gegen Morgen begannen die Streitkräfte der USA eine Versorgungsstruktur aufzubauen, die ihm eine unbegrenzt lange Aufenthaltsdauer in Marienborn ermöglichte. Der anderen Seite wurde damit signalisiert, daß man nicht nachgeben werde. Zudem bewog Washington die britischen und französischen Besatzungspartner dazu, ebenfalls Konvois loszuschicken, um den Kreml vor die Wahl zu stellen, entweder die Transporte aller Westmächte aufzuhalten oder den Eindruck einer willkürlich nur gegen die Amerikaner gerichteten Aktion hervorzurufen. Der Konflikt weitete sich so in einer Weise aus, die in Moskau nicht vorausgesehen worden war. Mit der Aussicht konfrontiert, die festgehaltenen Soldaten nicht wieder loszuwerden, suchte die sowjetische Militärführung schließlich die Affäre irgendwie zu beenden. Nach einundvierzig Stunden wurde die Blockade aufgehoben. ${ }^{82}$

Mit einer Note, die den amerikanischen Protest gegen das Vorgehen beantwortete, suchte der Kreml den Eindruck hervorzurufen, daß er auf der unnachgiebigen Haltung beharre. Er stellte sich auf den grundsätzlichen Standpunkt, die Instruktionen der USA an die Kommandeure der Konvois seien „für die sowjetischen Militärbehörden keineswegs bindend“. Die „Ansprüche der amerika-

1963, ebd., S. 615-618; Memorandum From Acting Secretary of State to President Kennedy, 26. 10. 1963 , ebd., S. 619 f.

81 Generalleutnant Ariko (mit ausdrücklicher Billigung von Armeegeneral Jakubovskij), Instrukcija po rabote pograničnych kontrol'no-propusknych punktov Marienborn i Novaves [= Babelsberg], 17. 10. 1963, AVPRF, 0742, 8, 61, 24, Bl. 34-41.

82 J. C. Ausland, a.a.O., S. 86-89; Telegram From the Department of State to the Embassy in Germany, 4. 11. 1963, in: FRUS 1961-1963, XV, S. 620f.; Telegram From the Embassy in Germany to the Department of State, 4. 11. 1963, ebd., S. 622 f.; Telegram From the Department of State to the Embassy in Germany, 5. 11. 1963, ebd., S. 624-626; Telegram From the Embassy in Germany to the Department of State, 7. 11. 1963, ebd., S. 626 f.; Armeegeneral I. Jakubovskij an E. Honecker, 6. 11. 1963, SAPMO-BArch, DY 30/3691, Bl. 176f. (dte. Ubers.), 178f. (russ.); A. Gromyko/R. Malinovskij/S. Brjusov an das ZK der KPdSU, 20. 11. 1963, AVPRF, 0742, 81, 61, 24, Bl. 70f.; Dokumente zur Deutschlandpolitik, a.a.O., IV, 9/2, S. 882 f. (Fußnote 5). 
nischen Militärbehörden“ seien „völlig haltlos, nach eigenem Ermessen die Handlungsweise der sowjetischen Vertreter am Kontrollpunkt beim Kontrollieren amerikanischer Militärangehöriger zu bestimmen. "Die amerikanische Seite habe „faktisch mit Vorbedacht und grundlos“ Zwischenfälle hervorgerufen, „um dann selbst Protest zu erheben." 83 Faktisch jedoch lenkte die UdSSR ein. Sie verzichtete darauf, weitere Kolonnen der USA auf den Transitstrecken zu behindern. Die Einsicht brach sich Bahn, man könne nicht zugleich gegen vitale amerikanische Berlin-Interessen Front machen und von Washington die Bereitschaft zum Abschluß anderer Übereinkünfte erwarten, von denen man sich Vorteile versprach. Vor die Wahl zwischen Konflikt und Kooperation gestellt, entschied sich Chruschtschow für die Zusammenarbeit.

\section{Ende der Berlin-Gepräche}

Gegenüber den Vertretern der angelsächsischen Mächte betonte die sowjetische Seite noch Anfang Oktober 1963 die Dringlichkeit einer Vereinbarung über den Abzug der Garnison aus West-Berlin. ${ }^{84}$ Im Laufe des Monats kam es nochmals zu Gesprächen, ohne daß eine Annäherung erzielt wurde. ${ }^{85}$ In Moskau hatte man freilich mit einer Vereinbarung kaum noch gerechnet. Als endgültig klar geworden war, daß man nicht mit amerikanischem Einschwenken auf die sowjetische Linie rechnen konnte, stufte Chruschtschow den Stellenwert der Berlin-Frage ein weiteres Mal herab. Wie es intern hieß, verzichtete die UdSSR darauf, einen Termin für eine Regelung zu nennen, und gab nur der Überzeugung Ausdruck, daß die Westmächte „einen Fehler zulassen würden, wenn sie die Lösung wie bisher endlos hinauszögerten.“ Diese höben zwar hervor, daß sie die „erstrangige Bedeutung“ der Frage anerkennten, doch meine man auf amerikanischer Seite, es gebe „gegenwärtig keine reale Möglichkeit zur Lösung des deutschen Problems“, auch wenn die Zeit darauf hinarbeite. Rusk habe zudem „Bezug darauf genommen, daß in den vergangenen zwei Jahren gewisse Veränderungen eingetreten seien, die das deutsche Problem seiner früheren Schärfe und Spannung entkleidet hätten. “ Unausgesprochen wurde deutlich, daß man sich damit abfand. Rusks Äußerung, die neue Regierung in Bonn unter Bundeskanzler Erhard sei gegenüber den sozialistischen Ländern aufgeschlossener und werde der Bildung technischer Kommissionen mit der DDR zustimmen, wurde zwar mit Skepsis aufgenommen, weckte aber doch Hoffnung. Mit den USA war man sich darin einig, Konfliktverschär-

83 Note der Regierung der UdSSR an die Regierung der Vereinigten Staaten, 21. 11. 1963, ebd., S. 921-923/Documents on Germany 1944-1985, Department of State Publication 9446, Washington 1985, S. 858-860. Die vorausgegangene Note der USA an die UdSSR, 6. 11. 1963, ebd., S. 856858.

84 Ausführungen Gromykos über Gespräche mit Rusk und Douglas-Home vor Delegierten der sozialistischen Staaten in New York (tschech.), 5. 10. 1963, in: Michal Reiman/Petr Luňák (Hrsg.), Studená válka 1954-1964. Sovětské dokumenty v českých archivech, Prag-Brünn 2000, S. 373376.

85 Siehe insbes. Memorandum of Conversation (Rusk - Gromyko), 10. 10. 1983, FRUS 1961-1963, Vol. V: Soviet Union, http:/www.state.gov/www/about_state/history/vol_v/360_369.html, S. 4-8; Memorandum of Conversation (Kennedy - Gromyko), ebd., S. 9-11. 
fungen in Berlin zu vermeiden, damit andere Probleme angepackt werden könnten. Das erzielte Einvernehmen über die Schaffung einer „günstigeren allgemeinen internationalen Lage“ schien dafür die nötigen Voraussetzungen zu bieten. ${ }^{86}$

Chruschtschow glaubte, nach der von ihm erwarteten Wiederwahl Kennedys im Herbst 1964 noch fünf Jahre Zeit für die Aushandlung von Verträgen und Übereinkünften mit Washington zu haben. Das mochte auch zu Fortschritten in Berlin führen. Diese Hoffnung wurde durch die Ermordung des amerikanischen Präsidenten jäh zerstört. Das war für den sowjetischen Führer ein schwerer Schlag, der ihn tief erschütterte. Von Kennedys Nachfolger Johnson versprach er sich wenig Verständigungsbereitschaft. ${ }^{87}$ Er begann sich um die Bundesrepublik zu bemühen, die er seit 1957/58 als Hauptfeind bekämpft hatte. Dort war gerade der langjährige Widersacher Adenauer durch Erhard abgelöst worden. Anders als die Parteichefs in Ostmitteleuropa glaubte Chruschtschow an eine sich entwickelnde Bereitschaft der Bundesrepublik zu einem neuen „Rapallo“. Die neue Bundesregierung werde $\mathrm{zu}$ enger wirtschaftlich-technischer Kooperation ohne Rücksicht auf die Westmächte bereit sein, denn die führenden westdeutschen Kreise seien primär an ökonomischen Erfolgen interessiert, suchten diese durch Kontakte mit der UdSSR zu erreichen und wollten sich die Chance dazu nicht länger wegen des Gegensatzes zur DDR entgehen lassen. Sie wüßten, daß sie für enge Handelsbeziehungen keinen politischen Preis fordern könnten und daß die deutsche Vereinigung nicht gegen UdSSR und DDR zu erreichen war. Der Kremlchef schöpfte daraus die Überzeugung, Erhard wolle die bisherige Westorientierung korrigieren. Die - mit seinem Wissen und Willen erfolgte - Einladung von Chruschtschows Schwiegersohn Adshubej in die Bundesrepublik sei als ein klares Signal zu betrachten. ${ }^{88}$

\section{Passierscheine für West-Berlin}

Angesichts des neuen sowjetischen Interesses an Zusammenarbeit und Verständigung mit der Bundesrepublik war der schlechte Eindruck besonders mißlich, den die Abriegelung West-Berlins in der Öffentlichkeit hinterließ. Der Kreml war aber keinesfalls bereit, auf die Mauer zu verzichten. Die Isolierung der Stadt von ihrem geographischen Umfeld und die Beeinträchtigung ihrer Lebens- und Entwicklungsmöglichkeiten sollten nicht beseitigt werden, hoffte man doch, die Stadt dadurch früher oder später zur politischen Kapitulation zu nötigen. Unerwünscht war jedoch, daß UdSSR und DDR vor aller Welt als Verursacher einer inhumanen Trennung von Verwandten und Freunden dastanden. Dieses Bild hatte Chruschtschow nie bieten wollen. Zwar hatte er sich 1961 nach langem Zögern davon überzeugen lassen, daß der Stopp der Massenflucht Vorrang vor allen anderen Überle-

86 Sowjetische Aufzeichnung, Teil 1: Voprosy germanskogo mirnogo uregulirovanija i normalizacii položenija v Zapadnom Berline, o.D. [handschriftlicher polnischer Eingangsvermerk: 31.X.63], AAN, KC PZPR XI A/81, Bl. 345-347.

87 W. Taubman, a.a.O., S. $604 \mathrm{f}$.

88 Aufzeichnung über ein Gespräch zwischen Chruščëv, Novotný, Gomułka und Ulbricht in Prag (tschech.), 21. 8. 1964, in: M. Reiman/P. Luňák, a.a.O., S. 379-387. 
gungen erhalten müsse, doch war ihm dabei ein ungutes Gefühl geblieben. Schon bald nach Sperrung der Sektorengrenze hatte er daher veranlaßt, daß den WestBerlinern die Genehmigung von Besuchen im Ostteil der Stadt angeboten wurde. Die Regelung war jedoch an damit verknüpften politischen Bedingungen gescheitert. Es war bei bloßer Propaganda geblieben, die längst unglaubwürdig geworden war. Dem Kremlchef war es - anders als der SED-Führung - darum nicht recht, daß West-Berlin völlig vom Kontakt mit der ostdeutschen Außenwelt abgeschnitten war. ${ }^{89}$

Zudem hoffte Chruschtschow nach wie vor, die West-Berliner durch Entgegenkommen nach und nach für sich gewinnen zu können, sobald sie erst einmal eingesehen hätten, daß es an der Seite des Westens für sie keine Zukunft mehr gebe. Ein probeweiser Genuß der Vorteile, die nach Schaffung der „selbständigen politischen Einheit“ zu erwarten standen, mochte den Haltungswandel fördern. Als der Rücktritt Adenauers abzusehen war, schien die Zeit zur Vorbereitung einer entsprechenden Initiative gekommen. Am 18. Februar 1963 stellte Abrassimow dem stellvertretenden DDR-Außenminister und Ulbricht-Vertrauten Otto Winzer die Frage, wie denn zu erklären sei, daß zwar die Westdeutschen, nicht aber die West-Berliner die Hauptstadt der DDR besuchen könnten. Der Angesprochene legte daraufhin dar, wie es wegen des Fluchtproblems dazu gekommen sei, und fügte hinzu, auf ostdeutscher Seite gebe es „bereits bestimmte Ideen“, wie sich die Frage regeln lasse. Dazu sei ein Abkommen mit dem West-Berliner Senat erforderlich. Zunächst müsse man aber warten, bis (nach den bevorstehenden Wahlen) ein neuer Senat gebildet worden sei. Der sowjetische Diplomat erwiderte, es müsse unbedingt etwas geschehen, denn das Fehlen einer einschlägigen Regelung wirke sich negativ aus. Vor allem verstünden die einfachen Leute in West-Berlin nicht, wieso ihnen Besuche bei ihren Verwandten verwehrt würden, während die Westdeutschen in die Hauptstadt der DDR reisen könnten. ${ }^{90}$

Das Gespräch verfehlte jedoch die gewünschte Wirkung. Daher ersuchte Abrassimow seinen Außenminister, dem Petitum durch eine Intervention in OstBerlin Nachdruck zu verleihen. Mitte Mai regte er an, „den deutschen Freunden zu empfehlen, die Frage der Zulassung der West-Berliner Einwohner in das Demokratische Berlin [wie der Sowjetsektor damals im Osten offiziell hieß] zu lösen." Zur Begründung führte er an, die Bevölkerung in beiden Teilen der Stadt vermerke das Fehlen einer solchen Regelung sehr übel. Die Schuld wurde freilich primär dem West-Berliner Senat angelastet. Der Botschafter ging noch nicht so weit, eine ausdrückliche Empfehlung anzuraten. ${ }^{91}$ Es ging anscheinend vorerst nur darum, die DDR-Regierung zu internen Vorbereitungen zu ermuntern, denen erst nach Klärung der politischen Lage im Westen nach Adenauers Rücktritt die Tat folgen sollte. Noch am 4. November ließ Abrassimow die Senatskanzlei in

89 Vgl. V. N. Beleckij, Pozicija GDR, Zapadnoberlinskogo senata, okkupacionnych vlastej trëch deržav i FRG po voprosu o dopuske zapadnoberlincev v Demokratičeskij Berlin, 16. 5. 1963, AVPRF, 0742, 8, 61, 23, B1. 7-21.

90 Zitiert bei A. M. Filitov, Sovetskij Sojuz, a.a.O., S. $175 \mathrm{f}$.

91 I. I. Il'ičëv an A. A. Gromyko, 16. 5. 1963, AVPRF, 0742, 2, 61, 23, Bl. 22 f. 
West-Berlin wissen, ihr Bemühen um eine Besuchsregelung werde auf dem vorgesehenen Weg nicht zum Erfolg führen. ${ }^{92}$

Um so mehr überraschte es den Senat, daß der Regierende Bürgermeister am 5. Dezember ein Schreiben des stellvertretenden DDR-Ministerratsvorsitzenden Abusch erhielt, in dem Verhandlungen hierüber vorgeschlagen wurden. Wie sich danach heraussstellte, ließ die SED-Führung die bis dahin gestellten politischen Bedingungen fallen, die als unannehmbar galten. Der Eindruck, daß die ostdeutsche Seite die Übereinkunft nunmehr ernstlich wollte, bestätigte sich bei der Erörterung der Einzelheiten vom 12. bis 17. Dezember. Das Ergebnis war eine Vereinbarung, der zufolge die West-Berliner für die Zeit vom 18. Dezember 1963 bis 5. Januar 1964 jeweils Tagespassierscheine für Besuche bei Verwandten ersten und zweiten Grades im Ostteil der Stadt beantragen konnten. Die Klausel, daß keine Einigung über gemeinsame Orts-, Behörden- und Amtsbezeichnungen erzielt wurde, und ein Verfahren, das den Vollzug von Hoheitsakten der DDR in WestBerlin vermied, machten die Übereinkunft für den Westen unter prinzipiellen Gesichtspunkten akzeptabel. Daß die ostdeutsche Regierung dies konzedierte, ist nur dadurch zu erklären, daß sie in enger Abstimmung mit dem Kreml bis hin zu Chruschtschow selbst agierte, wie aufgrund aller bekannt gewordenen Details anzunehmen ist. ${ }^{93}$

Aus der Sicht des Kreml sollte das Abkommen nicht nur die Öffentlichkeit beschwichtigen. Die Erwartung richtete sich auch darauf, daß daraufhin weitere Verhandlungen zwischen der DDR einerseits und West-Berlin und der Bundesrepublik andererseits in Gang kommen würden. ${ }^{94}$ Dabei wurde, zumindest auf längere Sicht, auch an Anerkennungsgewinne für den SED-Staat gedacht. Die sowjetischen Hoffnungen verstärkten sich, als der Regierende Bürgermeister, Willy Brandt, Bereitschaft zu einem Besuch in Ost-Berlin bekundete (wovon er dann freilich wegen eines intern erhobenen Einspruchs absah). Wie es scheint, erwog die Führung der UdSSR daraufhin noch weitergehende Schritte. Am 27. Dezember 1963 erklärten Mitarbeiter des Außenministeriums und des ZK-Apparats einem ostdeutschen Diplomaten während eines geselligen Beisammenseins, man müsse sich eine Argumentation überlegen für den Fall, daß die westliche Seite die Zulassung von DDR-Bürgern nach West-Berlin anspreche. Dabei ließen die sowjetischen Gesprächspartner den Einwand nicht gelten, die Frage stelle sich erst nach „Normalisierung“ der dortigen Verhältnisse, also nach Durchsetzung der Freistadt-Regelung. Sie meinten vielmehr, man könne den Dialog über eine derartige Regelung nicht von vornherein verweigern, wenn Brandt komme. Nach nochmaligem Widerspruch machten sie deutlich, daß es dem Kreml darum ging,

92 Gerhard Kunze, Grenzerfahrungen. Kontakte und Verhandlungen zwischen dem Land Berlin und der DDR 1949-1989, Berlin 1999, S. 80.

93 Steffen Alisch, Berlin - Berlin. Die Verhandlungen zwischen Beauftragten des Berliner Senats und Vertretern der DDR-Regierung zu Reise- und humanitären Fragen 1961-1972, Arbeitspapier des Forschungsverbundes SED-Staat, Nr. 31/2000, S. 50-58. Zu den Überlegungen und Auseinandersetzungen auf westlicher Seite siehe die Äußerungen des beteiligten amerikanischen Diplomaten James S. Sutterlin in: David C. Geyer/Bernd Schaefer (Hrsg.), American Détente and German Ostpolitiik, 1969-1972. Supplement to the Bulletin of the German Historical Institute No. 1, Washington/DC 2004, S. $153 \mathrm{f}$.

94 Dossier über die Haltung der Sowjetunion zur Deutschland- und Westberlin-Frage 1. 12. 19635. 1. 1964, 8. 1. 1964, PA-MfAA, C 974/71, Bl. 148. 
den Regierenden Bürgermeister und SPD-Vorsitzenden zum Fortschreiten auf der „Tutzinger Linie“ - also auf dem Weg, den Bahrs Rede über „Wandel durch Annäherung "95 vorgezeichnet hatte - zu ermutigen. ${ }^{96}$

\section{Freundschafts- und Beistandsvertrag mit der DDR}

Die sowjetische Führung mutete Ulbricht mit ihrem Ansinnen ein weiteres Mal den Verzicht auf Wünsche und Forderungen zu, die sie bis dahin unterstützt hatte. Der SED-Chef sollte der West-Berliner Bevölkerung entgegenkommen, die er lieber noch mehr unter Druck gesetzt hätte. Um ihm die bittere Pille ein wenig zu versüßen, zeigte sich der Kreml zu einem kleinen Zugeständnis hinsichtlich der westlichen Militärmissionen bereit. Zwar lehnte er es nach wie vor ab, diese auf Vier-Mächte-Recht beruhende Institution aufzuheben und der DDR die Souveränität darüber zu übertragen, sicherte jedoch der SED-Führung zu, „Maßnahmen für [eine] strengere Kontrolle“ zu ergreifen. Es sei vorgesehen, die „gegenwärtigen Instrumente zur Beschränkung und Erschwerung der [westlichen] Spionagetätigkeit zu verändern“, falls dies erforderlich sei. Die ostdeutsche Seite wurde aufgefordert, dazu Anregungen zu geben und gegebenenfalls „Tatsachen einer Verletzung der festgelegten Ordnung auf der Autobahn und Eisenbahn“ mitzuteilen. ${ }^{97}$

Auf der Ebene der großen Politik suchte der Kreml die SED-Führung durch den Abschluß des Freundschafts- und Beistandspakts vom 12. Juni 196498 für erlittene Unbill zu entschädigen. Es handelte sich um eine Ersatzvereinbarung für den weiterhin verweigerten Friedensvertrag. Diese verpflichtete die UdSSR unter anderem in allgemeiner Form dazu, den ostdeutschen Verbündeten bei der Verfolgung seiner Ziele in Deutschland und Berlin zu unterstützen. Sie war gehalten, „unbeirrt für die Beseitigung der Überreste des zweiten Weltkriegs, für den Abschluß eines deutschen Friedensvertrages und die Normalisierung der Lage in Westberlin auf seiner Grundlage ein[zu]treten." Die vertragschließenden Seiten kamen auch überein, „Westberlin als selbständige politische Einheit [zu] betrachten." Es fehlten jedoch wesentliche Elemente der früher zugesagten Friedensregelung: Das westliche Besatzungsregime wurde nicht für ungültig erklärt, eine Anerkennung der DDR durch Drittstaaten nicht gefordert. Zudem sah sich das SEDRegime dazu aufgefordert, in der begleitenden Erklärung „die allgemeinen Probleme des Vertrages in den Vordergrund zu stellen und sich nicht zu stark auf die deutsche Frage zu orientieren. "99 Das bedeutete den endgültigen Abschied von der Forcierung des Berlin-Konflikts.

Der Vertrag verlieh den politischen Verhältnissen Ausdruck, die sich in der vorangegangenen Zeit herausgebildet hatten. Der Kreml ließ es nicht mehr auf einen

95 Referat von Egon Bahr vor der Evangelischen Akademie Tutzing, 15. 7. 1963, in: Boris Meissner (Hrsg.), Die deutsche Ostpolitik 1961-1970. Kontinuität und Wandel, Köln 1970, S. 45-48.

96 A. M. Filitov, Sovetskij Sojuz, a.a.O., S. $177 \mathrm{f}$.

97 Armeegeneral I. Jakubovskij an E. Honecker, 14. 10. 1963, SAPMO-BArch, DY 30/3691, Bl. 169 (russ.), 168 (dte. Übers.).

98 Dokumente zur Deutschlandpolitik, a.a.O., IV, 9/2, S. 717-723 (dt. und russ.).

99 Vermerk Dr. Herder über Gespräch zwischen den stellv. Außenministern Bolz und Zorin, 9. 8. 1963, PA-MfAA, G-A 478, Bl. 99. 
offenen Streit um Berlin und Deutschland ankommen, vermied aber eine Beilegung des Konflikts. Gemäß der Linie, die Chruschtschow Anfang 1962 abgesteckt hatte, hielt der Kreml die Forderung nach Friedensvertrag und Freistadt-Regelung uneingeschränkt aufrecht und war weder zur Änderung des Standpunkts noch zu einem Modus vivendi bereit, der die Austragung des Gegensatzes entschärft hätte. Der sowjetische Führer meinte weiter, eine schwelende Auseinandersetzung sei für ihn von Vorteil. Er war noch immer davon überzeugt, daß die UdSSR durch die Entwicklungen in der Welt zunehmend begünstigt werde und darauf warten könne, bis ihr der Erfolg wie eine reife Frucht in den Schoß falle. 100 Er hielt es daher für richtig, alle Ansprüche voll aufrechtzuerhalten, auch wenn sie vorerst nicht realisierbar waren. ${ }^{101}$

Angesichts des vermeintlich großen Bonner Interesses an enger Zusammenarbeit mit Moskau glaubte Chruschtschow an die Möglichkeit wechselseitiger Annäherung, ohne auf seinen Standpunkt in der Deutschland- und Berlin-Politik zu verzichten. Grundsätzlich wollte er seine Ziele weiterhin durchsetzen und betrachtete die Ausübung latenten Drucks auf West-Berlin als dazu geeignetes Mittel. Deshalb vereinbarte er mit Ulbricht, die Stadt sei als „separate“ bzw. „selbständige politische Einheit“" zu behandeln, die mit der Bundesrepublik nichts zu tun habe. Dieser Realität müsse durch Abwehr der Bonner „Einmischungen“ in die inneren Angelegenheiten der Stadt Geltung verschafft werden. Scheinbar richtete sich der Einspruch nur gegen die Bindungen an den westdeutschen Staat und sparte die Westmächte aus. Tatsächlich jedoch bildete er den Schwerpunkt eines Kampfes, der dem Ziel diente, langfristig die westliche Position insgesamt zu erschüttern.

100 Vgl. Beseda tov. Chruščëva s učastnikami Tret'ej Vsemirnoj vstreči žurnalistov, in: Pravda, 27. 10. 1963.

101 Vgl. G. Žiljakov/V. Beleckij, O perežitkach i ostatkach okkupacionnogo perioda na territorii GDR, 22.7. 1963, AVPRF, 0742, 2,61, 23, Bl. 110-141. 